\title{
TWENTY-SEVEN CASES OF SYPHILITIC ANEURYSM OF THE THORACIC AORTA AND ITS BRANCHES \\ BY
}

\author{
JOHN BORRIE AND SELWYN G. GRIFFIN \\ From the Regional Thoracic Surgery Centre, Shotley Bridge Hospital, \\ Newcastle-upon-Tyne
}

(RECEIVED FOR PUBliCATION AUGUST 29, 1950)

The purpose of this paper is to review the treatment of aortic aneurysms and to discuss a series of 27 cases.

An aortic aneurysm in most instances is a progressive and ultimately fatal disease. Most body tissues are unable to withstand its steady encroachment. Pressure on the trachea or bronchus may produce obstructive and infective pulmonary lesions or even necrosis and perforation with sudden death. Natural cure may occur by clotting, especially in saccular aneurysms, but this is uncommon.

Colt (1948) stated that 1,500 patients die of aneurysm each year in England and Wales, and that its frequency has not been lessened by arsenical drugs. Untreated patients with aneurysm have a poor expectation of life. Colt (1927) has shown that, at the age of 42 years, in a series of 37 cases, a quarter died four months from the time of the first symptom, half before seven months, another quarter before 16 months. Aneurysms of the transverse aorta are especially serious; out of 219 patients, one half died under 10 months and only a quarter lived more than 20 months.

Blakemore (1945), who has studied aneurysms both from the points of view of pathology and haemodynamics, found that the blood, circulating under pressure through an unclotted saccular or fusiform aneurysm, created a total strain on the sac wall that varied with the square root of the surface area. Doubling the diameter of an aneurysm by growth increased the strain upon the sac by $100 \%$. Thus, in rapidly growing aneurysms, there is a vicious circle of increased strain upon a sac of diminishing strength. On the other hand, he stated that once the contents of an aneurysm had clotted, the physical laws governing solids obtained, wherein the total strain is reduced from the aggregate pressure exerted on the entire sac wall to that exerted on the mouth of the aneurysm alone.

As the nutrition and strength of the aneurysmal wall largely depend on collateral blood vessels from its neck, the more rapidly expanding aneurysms may outstrip their blood supply, with resulting areas of anaemic necrosis, and in certain situations rupture.

\section{HISTORICAL SURVEY}

\section{WIRING}

There is no effective medical treatment for an established aneurysm. A patient suffering from this disease is doomed, unless the aneurysmal growth can be checked by clotting and organization of the contents. In 1864 this was first attempted 
by Moore, who inserted fine silver wire into the sac. Various other attempts to promote clotting by inserting pieces of metal, watch springs, and other foreign bodies all failed because these small foreign bodies left the sac and entered the general circulation. In 1879 Filippi reported that Corradi had modified Moore's method. He inserted $40 \mathrm{~cm}$. of wire into the sac, and, after connecting the free end with a positive pole of a battery, placed the negative pole in the vicinity of the aneurysm. Hunner, of Baltimore, quoted by Emmert (1933), reviewed the cases treated by these methods before 1900 . Fourteen had been treated by Moore's method alone, and of these eight were thoracic and six abdominal aneurysms: only two (both abdominal) were cured (14\%). He also collected 23 cases which had been treated by the combined method, 17 thoracic and six abdominal ; four (17\%) of these (three thoracic and one abdominal) recovered.

Power and Colt (1903) found three major drawbacks to Moore's method. The surgeon punctured the aneurysm with a fine trocar and cannula from which blood was often freely flowing: the length of wire introduced depended on how soon kinking occurred and stopped further progress. Sometimes only a few inches were inserted instead of the few feet necessary. With constant handling, both by the surgeon and his assistants, it was difficult to maintain sterility. Finally, the wire frequently passed into the aorta.

In 1903 they treated a patient suffering from aneurysm of the abdominal aorta, into which they introduced 80 in. of silver wire, with a clotting surface of 3.7 sq. in. Necropsy, performed shortly afterwards, revealed that a loop of wire had passed up into the aortic arch. To avoid repeating this accident Colt later designed a simple and efficient apparatus by means of which an expanding wire wisp of known surface area could be introduced into the middle of the sac with maximum speed and minimum risks of sepsis and haemorrhage. It was ideally suited for saccular aneurysms, especially those adherent to the chest wall, and could be introduced under! local anaesthesia. The apparatus consisted of a trocar and cannula, a cartridge into which was loaded a wire wisp, and a piston to discharge the wisp into the aneurysm (Fig. 1). Various lengths of trocar, cannula, cartridge, and piston were available.

The wire wisps were made in three sizes:

(a) One wisp, $2 \frac{1}{2}$ in. long, containing 75 in. of wire, the surface area being $1 \frac{3}{4}$ sq. in.

(b) One wisp, $3 \frac{1}{2}$ in. long, containing 105 in. of wire, the surface area being $2 \frac{1}{2}$ sq. in.

(c) One wisp, 5 in. long, containing 150 in. of wire, the surface area being $3 \frac{1}{2}$ sq. in.

"They are of fine steel, very lissom, and are dull gilt so as to provide a finely granular molecular surface for clotting. White thrombus, formed on this surface, can only be removed by scraping the wire" (Colt, 1948). Electrocoagulation was possible with this apparatus, specially insulated cannulae being available.

In 1948 Colt reported on 32 patients wired by various surgeons. One patient with a thoracic aneurysm lived for six and a quarter years following wiring in 1931, while another with an abdominal aneurysm wired in 1910 lived 17 years 7 months completely relieved of symptoms. 


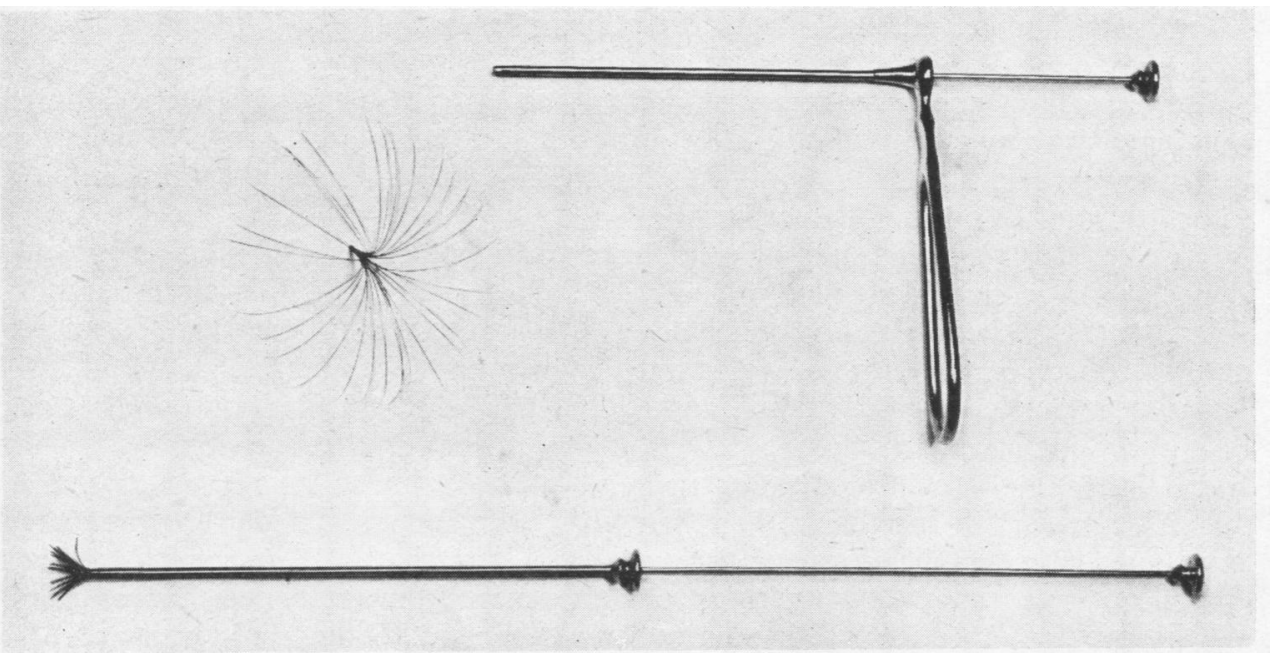

FIG. 1.--Colt's apparatus showing (a) wisp; $(b)$ trocar and cannula; $(c)$ loaded cartridge and piston.

\section{Electrothermic CoAgulation}

Blakemore and King (1938) modified the methods of Moore and Corradi, and advocate their method of electrothermic coagulation of aneurysms. Fine (34 gauge B and $\mathbf{G}$ ) insulated coin silver wire sterilized by autoclave was introduced through a special needle. A supply of 100 volts direct current was connected to the protruding end of wire. Each 10-metre segment of wire was heated to $80^{\circ} \mathrm{C}$. for a 10-second period, when a "tenacious clot-stimulating protein coagulum" formed on the wire.

In 1948 Blakemore reported an analysis of 63 cases of syphilitic aneurysms of the aorta so treated. There were 54 men, with an average age of 46 years, and nine women, with an average age of 38 years: 17 , or $27 \%$, of the 63 cases were living 11 to 2 years after treatment: 15 of the 17 were working and symptom-free: two, with aortic insufficiency, had to lead restricted lives. He was impressed with the relief of pain, the protection against rupture, and the overall rehabilitation of the patients.

\section{Cellophane Fibrosis}

In 1943 Harrison and Chandy reported a cure of an aneurysm of the subclavian artery from fibrosis induced by wrapping cellophane tape around the vessel. In 10 months partial arterial occlusion caused the aneurysm to become smaller, and in 19 months this process was complete. They stressed the importance of gradual occlusion of arteries, including the aorta, because in a comparable case treated by ligation a residual disability of the arm occurred.

Page (1939), who wrapped the kidneys of dogs in cellophane to produce experimental hypertension, drew attention to its irritating properties. Within two weeks a dense fibroblastic and collagenous deposit 3-5 mm. thick developed over the renal surface and further thickening continued indefinitely. Subsequent workers have stressed that some types of cellophane incite little or no foreign body reaction. 
In 1946 Poppe and De Oliveira described the results of cellophane wrapping of the abdominal aorta in experimental animals. They noted that one polythene variety of cellophane produced a marked fibrous tissue reaction. In one animal, examined two and a half months after operation, not only had the wall of the aorta been increased to six times its normal thickness, but the lumen had been reduced to one-third of its normal diameter.

While reporting the results of cellophane treatment of six syphilitic aneurysms, Poppe (1948) condemned blind wiring techniques. Although it is almost impossible to encircle the dilatation completely without encountering other vital structures or major arterial branches he had found that wrapping was most effective in fusiform aneurysms of the descending aorta. Indeed, he stated that contraindications to surgery included bronchial obstruction or erosion of the anterior chest wall. These latter two "contraindications," however, are almost always associated in our experience with saccular rather than fusiform aneurysms, and we believe they constitute definite indications for wiring by Colt's method. It appears to us that complications occurring from wiring techniques arise from faulty selection of cases. We believe that saccular aneurysms adherent or close to the chest wall are best treated by Colt's method, and that fusiform aneurysms are suited to cellophane wrapping.

\section{RESECTION}

Although resection has not yet been reported for syphilitic aneurysms, it has been successfully accomplished for non-syphilitic lesions. In 1944 Alexander and Byron first successfully removed an aneurysm of the thoracic aorta, measuring 11 by $8 \mathrm{~cm}$., together with a 7.5-cm. length of aorta, from a man aged 21 . From clinical and radiological evidence it was assumed to arise in connexion with an aortic coarctation. Boerema was able to excise one which arose at the line of suture following Crafoord's operation for coarctation of the aorta (Blickman, 1949). In 1950 Monod and Meyer resected an aneurysm of the aortic arch of a woman aged 20 without disturbing the continuity of the aortic lumen. Because of histological proof of necrosis in the media of the aneurysmal wall, he suggested that it arose as a dissecting aneurysm following an embolus to a vas vasorum, or from an arteritis associated with variations in blood pressure. All these patients survived operation.

\section{THE PRESENT REVIEW}

Between September 15, 1936, and January 5, 1950, 27 patients were admitted to the Northern Regional Thoracic Clinic for investigation and treatment of syphilitic aneurysms of the thoracic aorta and its branches.

\section{Pathology}

The ages of the patients ranged from 46 to 82 , with a mean of 58 . As there were 21 men and 6 women, men were to women in the proportion of $3 \frac{1}{2}$ to 1 .

The sites as diagnosed radiologically and/or by thoracotomy were as follows:

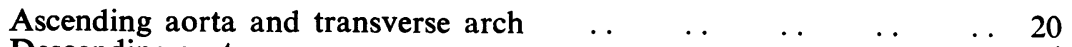

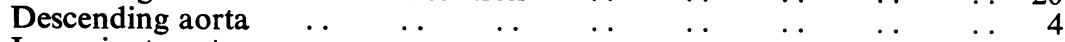

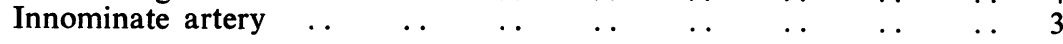


A double aneurysm was found on two occasions. In one patient both aneurysms were fusiform, and situated in the descending aorta; they were separated from each other by $3 \frac{1}{2} \mathrm{~cm}$. In the other, the proximal aneurysm was saccular and in the ascending aorta; the distal one, being unsuspected until necropsy, was fusiform and in the descending aorta.

\section{TYPE}

By fluoroscopy and examination of radiographs, 21 of the aneurysms were judged to be saccular and six fusiform in shape, a finding at variance with Poppe and De Oliveira's (1946) assertion that fusiform are more frequent than saccular aneurysms. Our experience does not necessarily represent a true incidence rate of the two varieties of aneurysm.

\section{SYMPTOMS}

The onset of symptoms was usually insidious; but in two cases it was sudden. One (No. 2289) complained of sudden dyspnoea, loss of voice, and tightness in the neck "like a collar stud pressing on the wind pipe." After two further attacks at monthly intervals, he died from bronchopneumonia. The other (No. 4817) experienced a sudden pain in the right infra-clavicular fossa radiating down the inner side of the right arm. This was associated with a saccular aneurysm of the aortic arch.

The duration of symptoms varied from $1 \frac{1}{4}$ to 24 months, with a mean of nine months.

Symptoms could be readily ascribed to pressure effects of the aneurysms.

Cough and Dyspnoea.-This, the commonest group of symptoms, was due to pressure on the trachea or bronchi, with "steadily increasing dyspnoea " found in 16 , and cough with sputum in 14 patients. Although tracheal compression alone was the most common cause of chronic cough, yet in some the trachea and bronchi were so compressed that a definite obstruction occurred with resulting pulmonary infection and chronic suppurative bronchitis (Fig. 2). In one patient compression caused collapse of the left lung and death (No. 2851).

Voice Changes.-Eight patients complained of voice changes, varying from huskiness to complete loss of voice: four of these were bronchoscoped. One showed left vocal cord paralysis, and three narrowing of the trachea or bronchi.

Pain.--Pain varied in site, constancy, and severity. Eleven patients were affected. In one pain was felt only at night. Usually it occurred night and day, and was described as "burning" or "gnawing." It was often associated with "pressure" against bone, e.g., the vertebral column, sternum, or anterior ends of ribs.

Four patients had "angina pectoris." One at necropsy showed patchy fibrosis of the myocardium and well-marked patchy atheroma of the coronary arteries but no thrombus.

Lump.-In three patients erosion of the chest wall produced a visible lump. Two are alive and well after "wiring." The other, who refused treatment, has been observed for nine months.

Haemoptysis.-Four complained of haemoptysis. A red tinging of sputum occurred in three, and a brisk half-pint bleed in the fourth. This last patient died a month later at home, having refused treatment. Of the other three, the first 


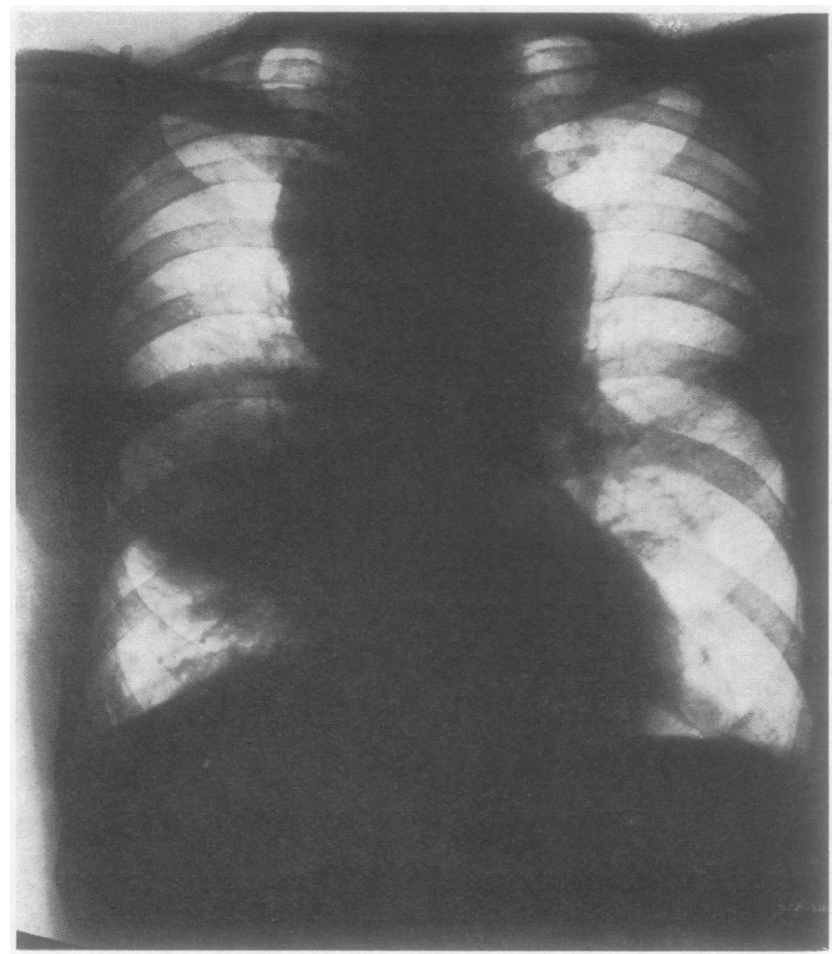

FIG. 2.-Partial collapse of right lower lobe from bronchial obstruction due to aneurysm (Case No. 5209).
(No. 3433), a labourer, aged 64 , with a saccular aneurysm of the aortic arch and 2 oz. of blood-stained sputum daily, died two days after admission. Necropsy showed a saccular aneurysm arising from the aortic arch extending into the upper lobe of the left lung. It had eroded and ruptured into the left upper lobe bronchus. The second (No. 5062), a labourer, aged 47, had a fusiform aneurysm of the arch and descending thoracic aorta, a s s oc ia ted with cough and blood-stained s putu m. Thoracotomy showed that the aneurysm had invaded the lower lobe of the left lung. The third (No. 5209) a van driver, aged 57 , had a saccular aneurysm of the

aortic arch associated with brassy cough and blood-stained sputum. On admission he had severe bronchopneumonia of the right lung caused by almost complete antero-posterior compression of the trachea. As the sputum was rusty in colour, rather than bright red, it is more likely that the haemoptysis resulted from the severe respiratory infection or congestion than from a leaking aneurysm. In this group of cases haemoptysis probably resulted from two causes: either from aneurysmal compression of bronchi or trachea producing congestion and infection, or from aneurysmal leak into a lung.

Loss of Weight.-Eight patients complained of loss of weight, varying from a few pounds to as much as one stone in three months.

Unsuspected Aneurysms.-In a patient (No. 3319), a blacksmith, aged 55, who had a routine radiological examination following pneumonia, a fusiform aneurysm of the aortic arch was found. He refused treatment.

\section{Physical Signs}

Lump.-As previously stated, three patients noticed a lump on the chest wall. Each of these lumps pulsated. One was situated in the right infra-clavicular fossa, another in the left infra-clavicular fossa, and the third to the right of the sternum. Precordial pulsation was present in nine other patients. 
Respiratory System.-Signs related to aneurysmal compression of trachea can be tabulated as follows:

\begin{tabular}{|c|c|c|c|c|c|c|c|c|}
\hline "Brassy cough" & .. & . & . & . & & & & . \\
\hline Stridor $\quad$.. & .. & .. & $\cdots$ & $\cdots$ & $\cdots$ & $\cdots$ & $\ldots$ & \\
\hline Hoarseness .. & .. & .. & . & $\therefore$ & .. & . & .. & \\
\hline Tracheal tug ... & .. & .. & .. & . & .. & . & . & \\
\hline Tracheal displacemen & & .. & . & 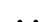 & 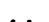 & 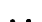 & .. & \\
\hline
\end{tabular}

Eight patients also had clinical signs of bronchial infection; one presented with collapse of lung and one with obstructive emphysema.

Although "brassy cough" occurred in four patients, in only one was a left vocal cord paralysis seen. Bronchoscopy, in fact, showed that the cough was due to severe narrowing of the tracheal lumen. A similar cough is sometimes heard in patients suffering from carcinoma of the bronchus causing partial occlusion of the trachea or main stem bronchi. In all four patients the aneurysms were saccular ; in three it was situated in the arch of aorta, and in one in the innominate artery.

Cardiovascular System.-Gross left ventricular hypertrophy and right heart failure were each found three times. In five cases "to and fro" murmurs were heard at the base of the heart or over the swelling. Mitral systolic or aortic systolic murmurs were present on five occasions.

In five patients with no evidence of right heart failure, cervical vein engorgement suggested superior vena caval obstruction.

Six cases of the series showed significant changes in pulse or blood pressure. In one (No. 3942), a feeble left pulse and low left arm blood pressure indicated involvement of the left subclavian artery. (E.g., while the blood pressure in the right arm was $260 / 130 \mathrm{~mm}$. $\mathrm{Hg}$ and the right pulse strong, the left arm blood pressure was $130 / 30 \mathrm{~mm} . \mathrm{Hg}$ and the left pulse weak.)

\section{INVESTIGATIONS}

Wassermann Reaction.-The Wassermann reaction was positive in 24 cases.

Radiographs.-Both radiological and screening examination proved most helpful in localizing the lesion accurately. Screening also proved invaluable in detecting the degree of expansile pulsation within the aneurysmal mass. Sometimes it was impossible to say whether the pulsation was expansile or transmitted from heart and great vessels. Some, however, showed no pulsation. Penetrating films of sternum, ribs, and spine were taken in search of bone erosion. Barium swallow was also used to assess the degree of oesophageal obstruction and displacement by the aneurysm (Fig. 3).

If there was still doubt as to the continuity of the mass with the aortic arch, then, after finding the most suitable angle by screening, oblique tomograms were taken to demonstrate the connexion between the two. If lateral tomograms are taken, centred on the mediastinum, one or two cuts may incidentally show the amount of tracheal obstruction, a point well illustrated in Fig. 4. Here the aneurysm was causing such tracheal compression that the patient was unable to lie down without becoming violently dyspnoeic. It was only when an endotracheal tube had been passed, under local anaesthesia, beyond the obstruction that it was possible 


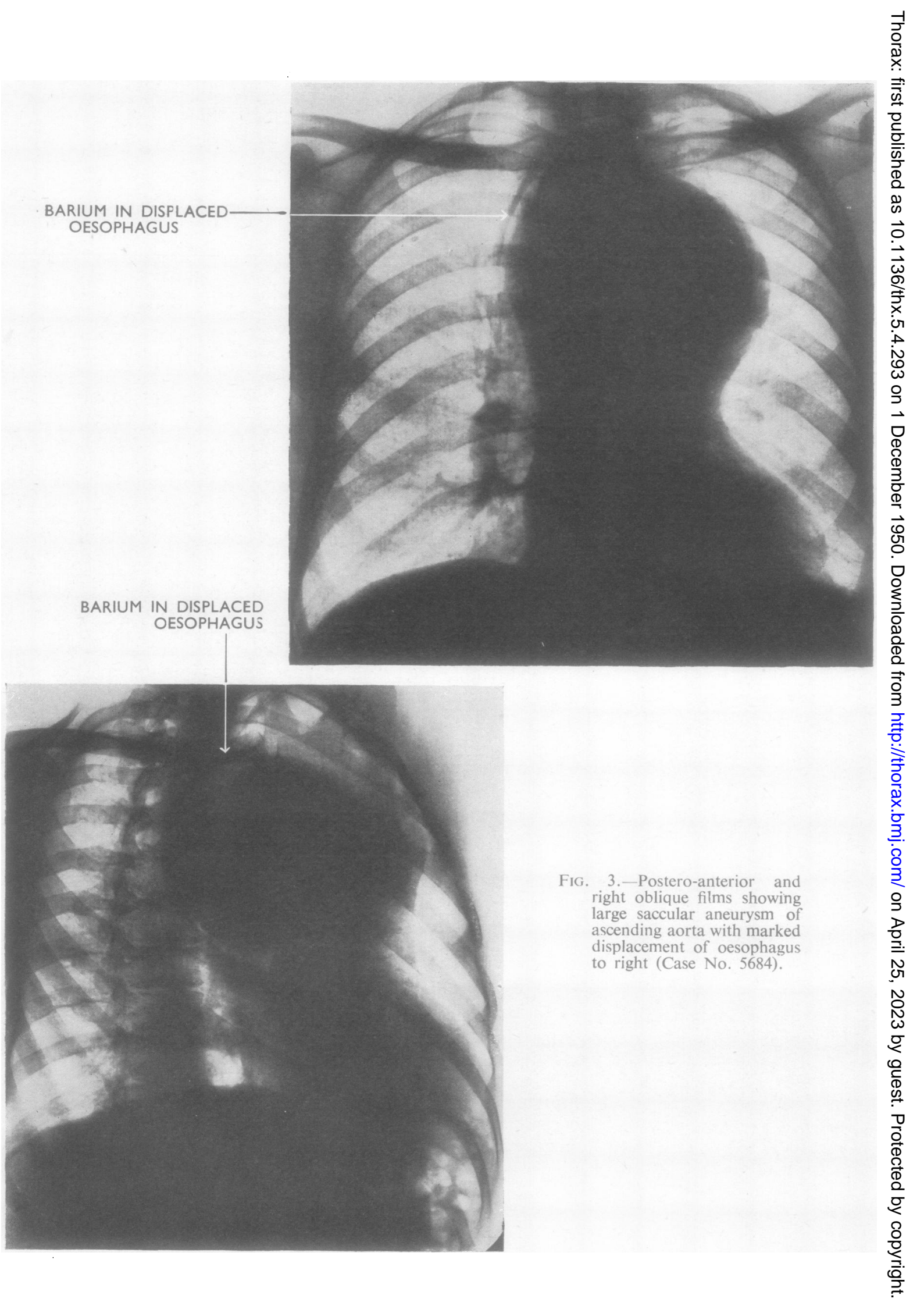




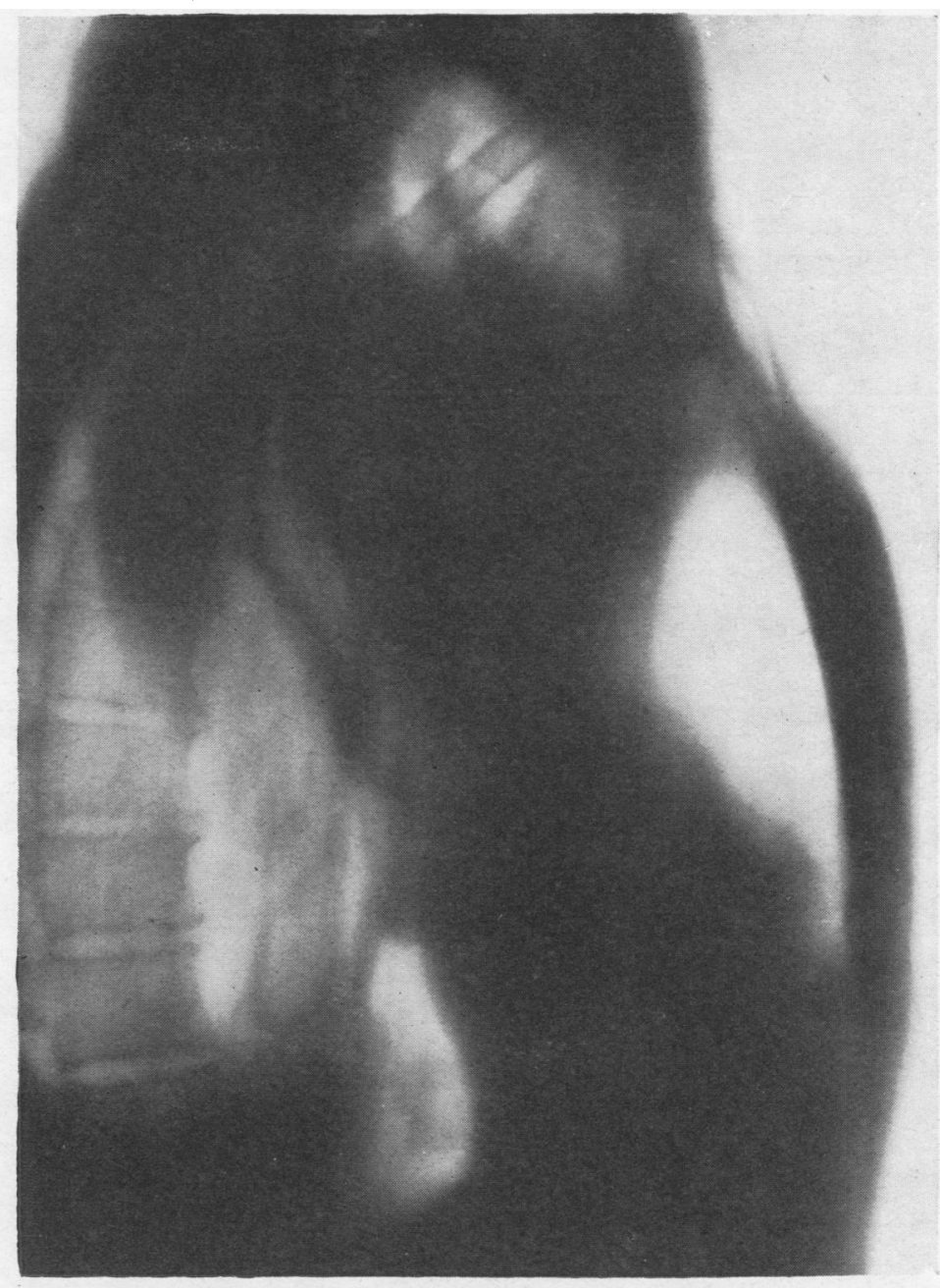

FIG. 4.-Right lateral tomogram ( $15 \mathrm{~cm}$.), with endotracheal tube in position, demonstrating severe degree of tracheal obstruction (Case No. 5209).

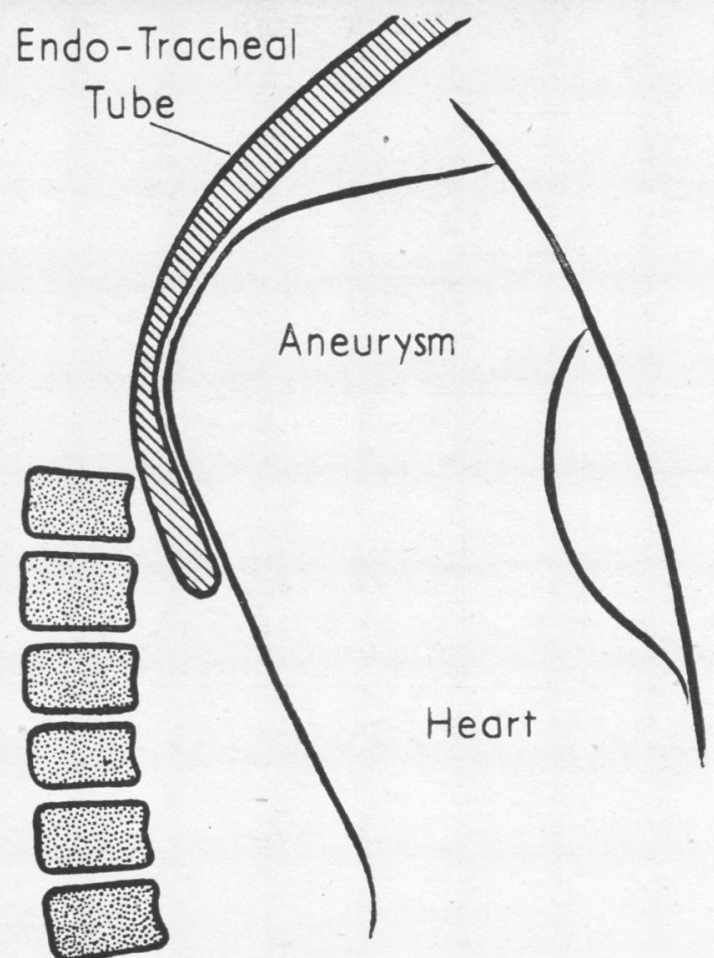


to relieve the patient's distress and provide sufficient airway to allow of taking tomograms.

Although angiocardiography was not used during the investigation of this particular series, it has proved valuable in other similar cases.

TABLE I

ANALYSIS OF BRONCHOSCOPIC FINDINGS

\begin{tabular}{|c|c|c|c|c|}
\hline $\begin{array}{c}\text { Serial } \\
\text { No. }\end{array}$ & $\begin{array}{l}\text { Clinic } \\
\text { No. }\end{array}$ & Aneurysm & $\begin{array}{l}\text { Voice } \\
\text { Change }\end{array}$ & Finding \\
\hline 1 & 530 & Saccular: aortic arch & & $\begin{array}{l}\text { Trachea narrowed in lower third by anterior } \\
\text { compression: pulsation }\end{array}$ \\
\hline 2 & 568 & $\begin{array}{l}\text { Saccular: ascending } \\
\text { aorta }\end{array}$ & & $\begin{array}{l}\text { R. stem bronchus narrowed below } R \text {. upper- } \\
\text { lobe bronchus by bulging in of anterior and } \\
\text { medial wall: pulsation }\end{array}$ \\
\hline 3 & 819 & Saccular: aortic arch & & $\begin{array}{l}\text { Pulsating bulge in postero-medial wall of } R \text {. } \\
\text { and L. stem bronchi }\end{array}$ \\
\hline 4 & 1175 & $\begin{array}{l}\text { Fusiform: descending } \\
\text { aorta }\end{array}$ & & Normal bronchial findings \\
\hline 5 & 2851 & Saccular: aortic arch & Yes & $\begin{array}{l}\text { Left main bronchus completely occluded by } \\
\text { extra bronchial pressure from " non-pulsating } \\
\text { mass." Pus exuded through stenosed area. } \\
\text { Biopsy attempted; aneurysm ruptured, with } \\
\text { sudden death }\end{array}$ \\
\hline 6 & 2944 & $\begin{array}{l}\text { Saccular: descending } \\
\text { aorta }\end{array}$ & & $\begin{array}{l}\text { Left bronchus was distorted ard slit-like. Gross } \\
\text { pulsation } L \text {. side of trachea and L. main } \\
\text { bronchus }\end{array}$ \\
\hline 7 & 4719 & Saccular: aortic arch & & $\begin{array}{l}\text { Carina foreshortened by antero-posterior com- } \\
\text { pression }\end{array}$ \\
\hline 8 & 5062 & $\begin{array}{l}\text { Fusiform: arch and } \\
\text { descending aorta }\end{array}$ & Yes & $\begin{array}{l}\text { Bulging, pulsating mass pushing in the left } \\
\text { tracheal wall and in posterior wall of } L \text {. main } \\
\text { bronchus }\end{array}$ \\
\hline 9 & 5209 & Saccular: arch of aorta & Yes & $\begin{array}{l}\text { Antero-posterior compression of trachea; just } \\
\text { above carina wellnigh totally obstructed by } \\
\text { pulsating swelling, except for narrow slit on } \\
\text { R. side }\end{array}$ \\
\hline 10 & 5241 & $\begin{array}{l}\text { Saccular: innominate } \\
\text { artery }\end{array}$ & & $\begin{array}{l}\text { Two inches below vocal cords, trachea was } \\
\text { narrowed to half size by external swelling on } \\
\text { anterior and } R \text {. lateral surfaces. No } \\
\text { obvious pulsation }\end{array}$ \\
\hline 11 & 5584 & Saccular: arch of aorta & Yes & $\begin{array}{l}\text { Paralysed L. vocal cord. Bulging into } L \text {. } \\
\text { lateral wall of trachea above carina, which } \\
\text { was greatly broadened. L. stem bronchus } \\
\text { almost completely occluded. R. stem nar- } \\
\text { rowed }\end{array}$ \\
\hline 12 & 6135 & Saccular: aortic arch & & $\begin{array}{l}\text { Cords normal. Trachea compressed to half } \\
\text { size in lower third from anterior and left } \\
\text { lateral aspects. No obvious pulsation }\end{array}$ \\
\hline
\end{tabular}


Bronchoscopy.-Bronchoscopy was important in assessing the state of the trachea and its mucosa, the site of tracheal obstruction, whether such was pulsating, and the character of any bronchial secretions. It also provided direct evidence of the increase of tracheal lumen following successful wiring of the aneurysm. Endobronchial pulsation per se is not diagnostic of aortic aneurysm; it is sometimes seen in patients suffering from bronchial carcinoma.

The amount of tracheal narrowing or deformity was no guide to imminence of rupture into the trachea. One patient (No. 5209) who had almost complete tracheal obstruction is alive and working 18 months after wiring. On the other hand, another patient (No. 5241), with a small degree of right antero-lateral compression of the tracheal wall from an innominate aneurysm, died from endotracheal haemorrhage two weeks after distal ligation of the right common carotid and right subclavian arteries.

Bronchoscopy is not without danger. During bronchoscopic investigation in one of our patients (for a possible lung neoplasm) an unsuspected aneurysm ruptured into the bronchus causing sudden death.

Electrocardiography. - In the later cases electrocardiographic tracings were made. The findings varied: usually a left axis deviation was found and sometimes myocardial degeneration was indicated by inverted $\mathrm{T}$ waves in leads 1 and 2 .

\section{DIAGNOSIS OF ANEURYSM}

A history of steadily increasing dyspnoea, voice changes, brassy cough, pain in the chest, and the presence of a pulsating lump on the anterior chest wall suggest the diagnosis. This is supported by a positive Wassermann reaction and by typical radiological findings. It is important to watch for expansile pulsation by both fluoroscopy and bronchoscopy. In doubtful cases specially sited oblique or lateral tomograms will help to establish that the mass is aortic in origin. If doubt still exists, angiocardiography may clinch the diagnosis.

\section{ANEURYSMS OF THE INNOMINATE ARTERY}

Diagnostically, innominate aneurysms are most interesting. Three occurred in our series.* The patients complained of a gnawing, intermittent pain beneath the right clavicle, a tightness at the root of the neck, and shortness of breath. Deep palpation behind the clavicle, preferably with the patient's head turned to the right, revealed a retro-clavicular pulsating mass. Radiological examination showed tracheal compression, expansile pulsation, and oesophageal displacement. Bronchoscopy revealed tracheal narrowing. A positive Wassermann reaction helped to ? distinguish the tumours from other swellings in this region, such as retrosternal goitre, bronchial carcinoma, thymic tumours, neurofibromata, or oesophageal pouch (Fig. 5a).

The following three case summaries illustrate these points.

\section{CASE REPORTS}

Case 1.-(No. 2289) A barman, aged 64, was admitted on March 18, 1945, with a history that in December of 1944 he had experienced a sudden onset of severe shortness of breath, loss of voice, and tightness in the neck. He had a retrosternal ache, cough,

${ }^{*}$ See addendum. 
Fig. 5.-(a) Postero-anterior film showing saccular innominate aneurysm compressing right side of trachea (Case No. 5241). (b) Two weeks after distal ligation the patient died from rupture into trachea. Post-mortem specimen, anterior view, showing aneurysm partially filled with laminated clot. (c) Post-mortem specimen, posterior view, showing site of aneurysmal rupture into trachea, $1 \frac{1}{2}$ in. above carina.
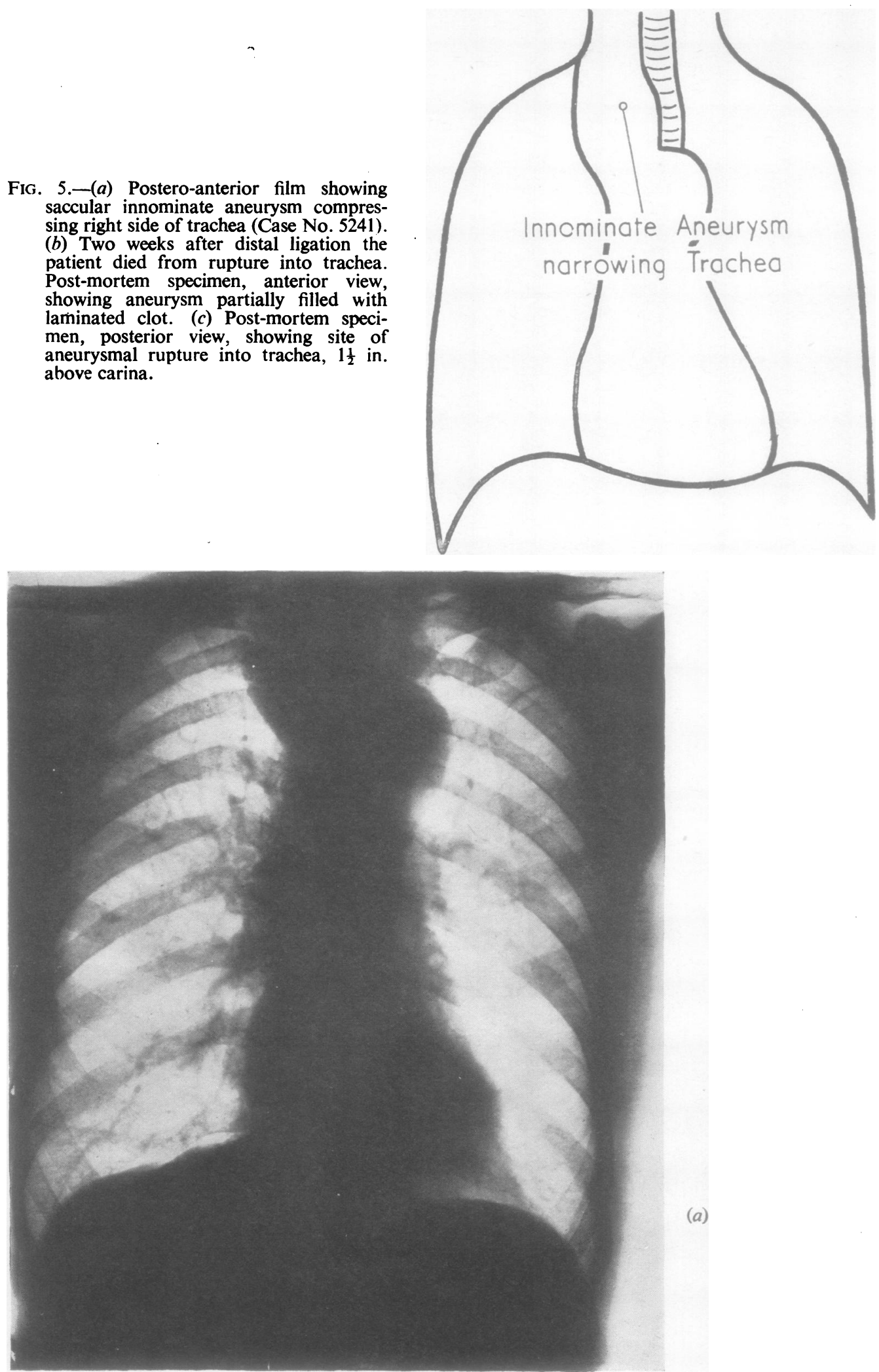


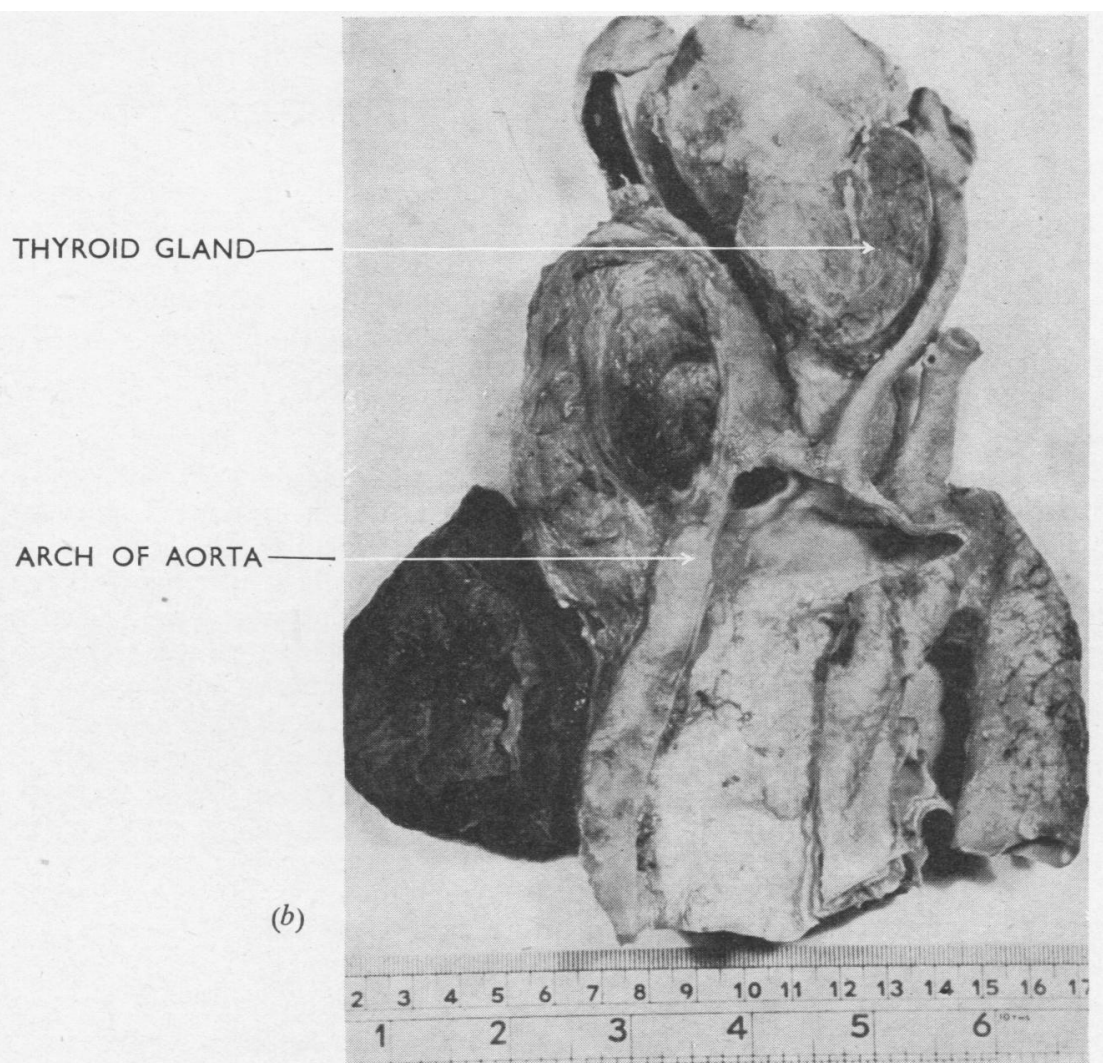


and copious white, frothy sputum. His pulse was $100 / \mathrm{min}$., respirations $26 / \mathrm{min}$., and blood pressure $112 / 60 \mathrm{~mm}$. $\mathrm{Hg}$ in the right arm and $130 / 60 \mathrm{~mm} . \mathrm{Hg}$ in the left arm.

There was a loud inspiratory stridor. The trachea was deviated to the left by a pulsating swelling behind the right side of the manubrium sterni and a "to and fro" murmur was present over this swelling. He had physical signs of bronchopneumonia at the base of the right lung. Screening confirmed the presence of an aneurysm together with partial collapse of the right lung. Six days later he died from bronchopneumonia. Necropsy was refused.

Case 2.-(No. 4138) A housewife, aged 82, admitted on August 22, 1947, complained of tightness in the chest, increasing shortness of breath on exertion during the last eight months, a burning retrosternal pain, and loss of weight. Recently, she had developed coligh and sputum. She had gross stridor, a loud "brassy" cough, and distended veins over the right upper chest. The blood pressure was $200 / 90 \mathrm{~mm}$. Hg.

Though the mass was rather posterior, the diagnosis was considered to be either a retrosternal goitre or aneurysm. Fluoroscopy revealed a rounded opacity, the size of a duck's egg in the superior mediastinum, pushing the trachea forwards and to the left and the oesophagus to the left. The Wassermann reaction was negative. Because of increasing dyspnoea during investigation, the lump was explored as an emergency on August 29, 1947, through a low cervical incision. An aneurysm of the innominate artery was found. In an attempt to decompress the aneurysm, the pretracheal muscles were only partially resutured. The signs and symptoms of superior mediastinal obstruction steadily improved. She lived in comfort until December, 1949, when she died from cerebral haemorrhage.

Case 3.-(No. 5241) An engineer, aged 59, admitted on January 5, 1949, gave a history of an attack of bronchitis four months previously, with dyspnoea, cough, and haemoptysis, as well as a gnawing, intermittent pain under his right clavicle. The blood pressure was $190 / 96 \mathrm{~mm}$. $\mathrm{Hg}$ in both arms.

He had a firm pulsating mass behind the manubrium sterni and right clavicle. The heart was normal in size and the second sound accentuated at the aortic area. The trachea was central; there was no tug. Screening revealed a swelling in the superior mediastinum with no gross pulsation. The oesophagus was displaced a little to the left. At bronchoscopy the trachea was seen to be narrowed 2 in. below the vocal cords by external pressure on the right antero-lateral aspect. The lumen was reduced to half its normal diameter. A diagnosis of aneurysm of the innominate artery was made. On February 10, 1949, he was explored through a T-shaped cervical incision with partial resection of the right clavicle and sternal splitting. The upper part of the aneurysm and right common carotid artery were exposed. The aneurysm was found to involve the whole of the innominate artery and to arise directly from the aorta. Its stoma seemed to be $\frac{3}{4}$ in. in diameter. Any form of proximal ligature or control was considered impossible. The common carotid artery was clamped with a Blalock clamp for seven minutes, and, as no change in the pupil was seen, this artery was tied in continuity with strong silk.* The second part of the right subclavian artery was then exposed and clamped for five minutes before being tied in continuity. It was proposed to wire the aneurysm in the third post-operative week : but two weeks after operation the aneurysm ruptured into the trachea and the patient died.

Subsequent examination of the specimen showed that the aneurysm was almost completely occluded by a firm, well-laminated clot (Figs. $5 b$ and $c$ ). Only a little blood escaped into the trachea, but this was sufficient to cause massive bilateral pulmonary collapse and death. The peri-aneurysmal matting and apparent thinness of the wall beside the trachea would have made any dissection for cellophane wrapping impossible.

* See addendum. 


\section{TREATMENT}

It is not proposed to discuss the medical treatment, but some of our patients were treated conservatively. Antisyphilitic treatment should be in the hands of a neurologist.

\section{Conservative Treatment}

Eleven of the 27 patients had no surgical treatment, either because they refused it or because the lesion was not considered suitable. Two others had surgical explorations to see if surgery could help. Of these 13 , two have not been traced. Four of the remaining 11 died suddenly from rupture of the aneurysm over a period ranging from one day to 13 months; one died from pneumonia, one from heart failure, and one from exhaustion following oesophageal obstruction due to aortic aneurysm. These seven patients all died within 15 months of diagnosis; two are still alive and have been observed for the last nine months.

The tenth (No. 568), an engineer of the Mercantile Marine, lived six years. He first reported on February 28, 1942, with symptoms of increasing dyspnoea. The pulse was "Corrigan" in type; blood pressure was $130 / 76$. There was an area of dullness and a "to and fro" heart murmur over the right border of the sternum. Radiography showed a large round right mediastinal shadow, and bronchoscopy a grossly pulsating narrowing of the right main bronchus below the right upper lobe orifice. Thoracoscopy was of no aid in diagnosis. A diagnosis of saccular aneurysm (Fig. 6) of the aorta or of the heart was made and he was given anti-syphilitic treatment and discharged. In 1947 he was still at work; his only cómplaint was breathlessness on exertion. The blood pressure was $160 / 80 \mathrm{~mm}$. $\mathrm{Hg}$ in both arms. An electrocardiogram showed inverted $T$ waves in leads 1 and 2 suggestive of myocardial degeneration. On February 25, 1948, he was readmitted with congestive heart failure.

Because there was little radiological evidence of change in his mediastinal shadow since 1942, and because it was felt that the original diagnosis might have been wrong and that the shadow was a mediastinal dermoid cyst now causing heart failure, on May 28, 1948, he was explored through a right thoracotomy. The firm tumour was found to be an aneurysm. Twenty-four hours later he died. Necropsy showed an aneurysm of the ascending aorta (size of an infant's head), firmly clotted.

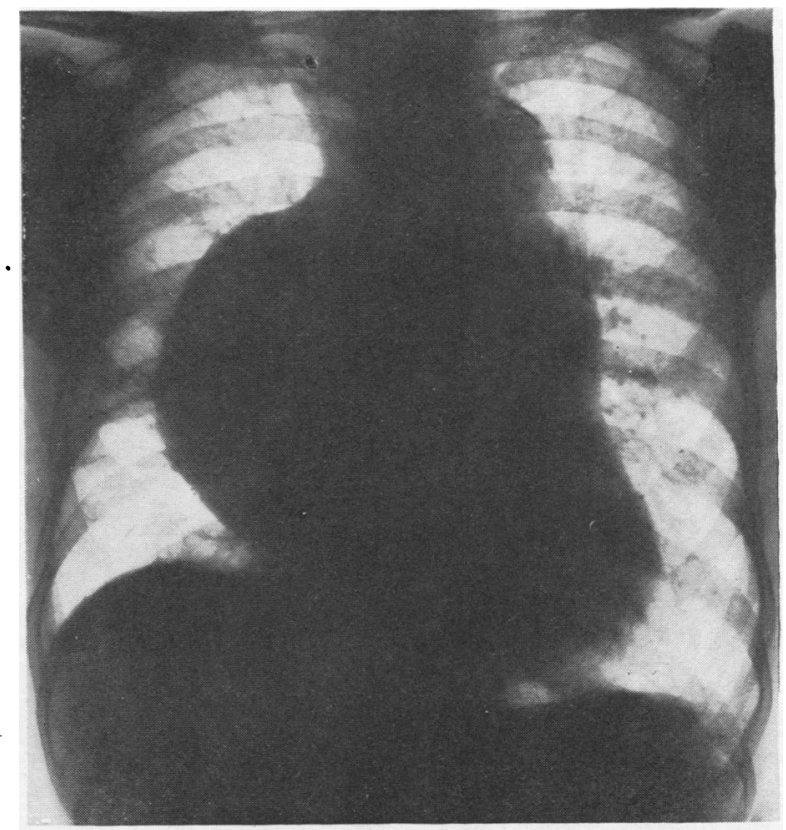

FIG. 6.-Saccular aneurysm of ascending arch of aorta (Case No. 568). At necropsy the aneurysm was seen to be filled with a mixture of stratified brown clot and fresh red clot. 


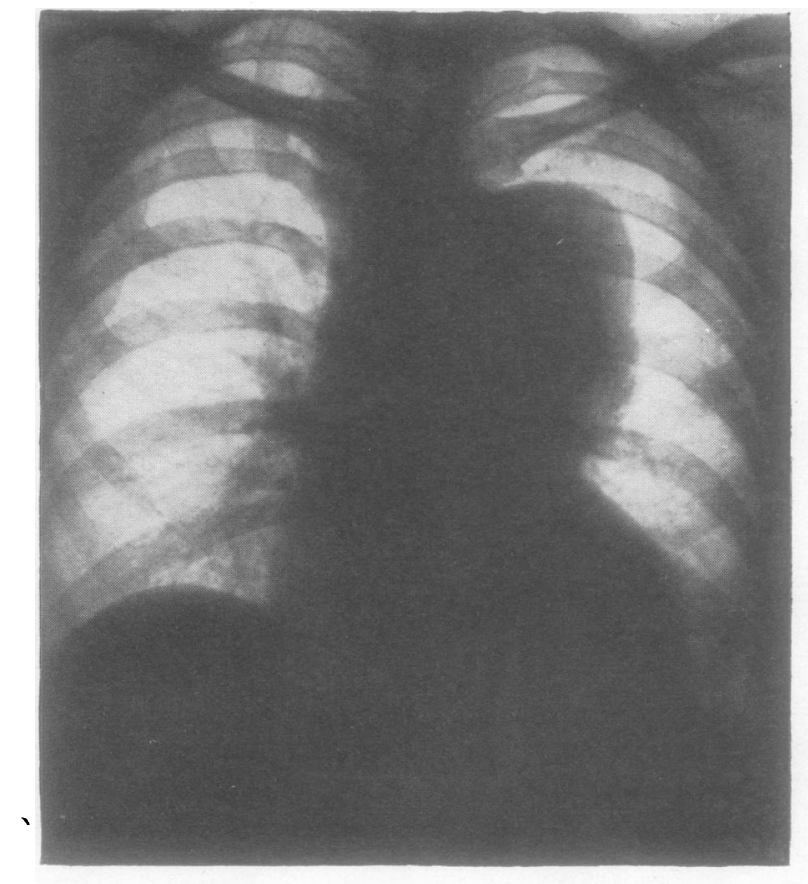

FIG. 7.-(a) Pre-operative postero-anterior and lateral films showing fusiform aneurysm of the descending aorta (Case No. 3363). (b) Post-mortem specimen (external view) three years three months later seen from in front and showing aneurysm still covered by cellophane. (c) Post-mortem specimen (internal view) showing aneurysm opened from behind, and firm clot lining thickened syphilitic aortic wall. The lumen of the aorta was not diminished.
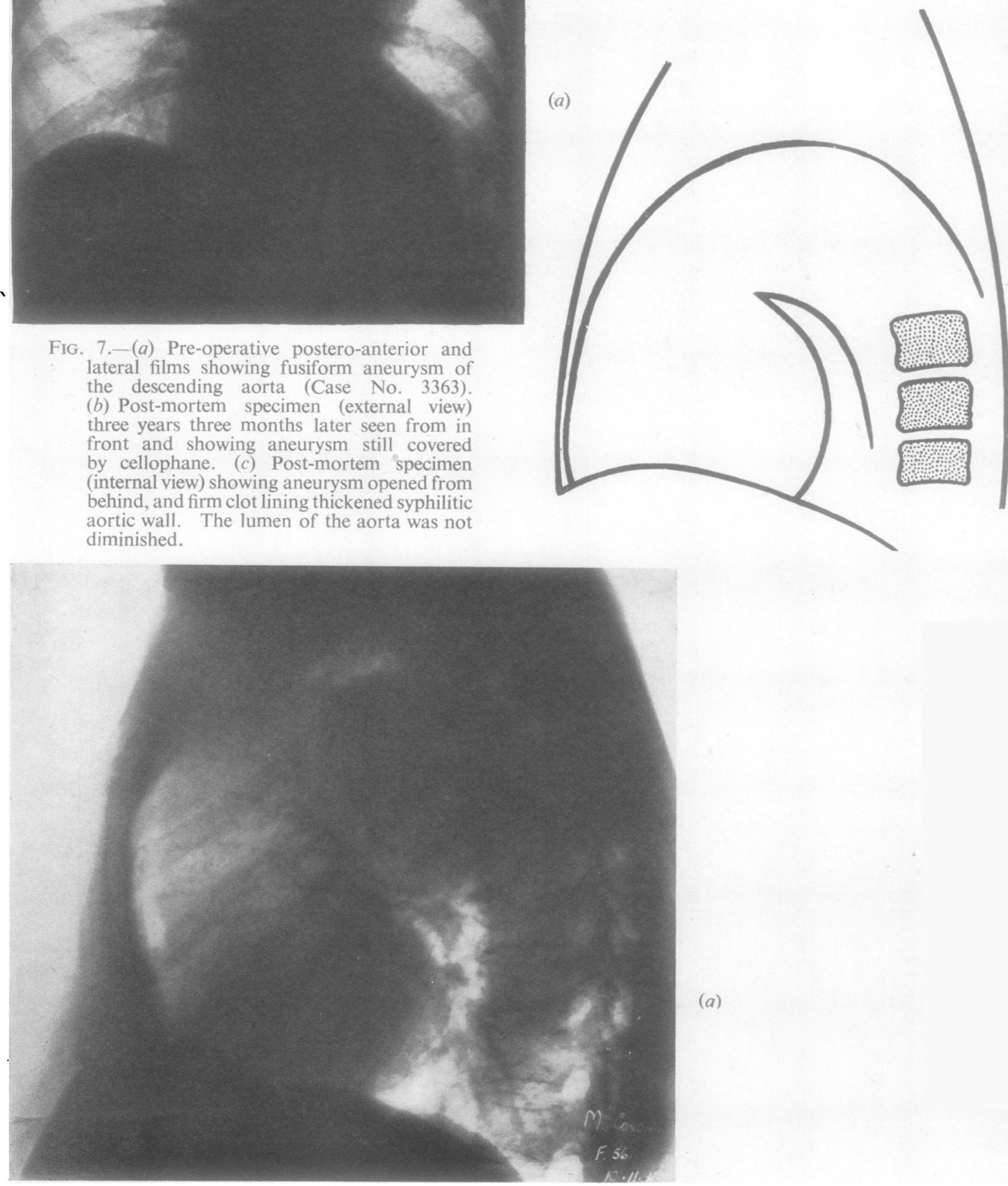

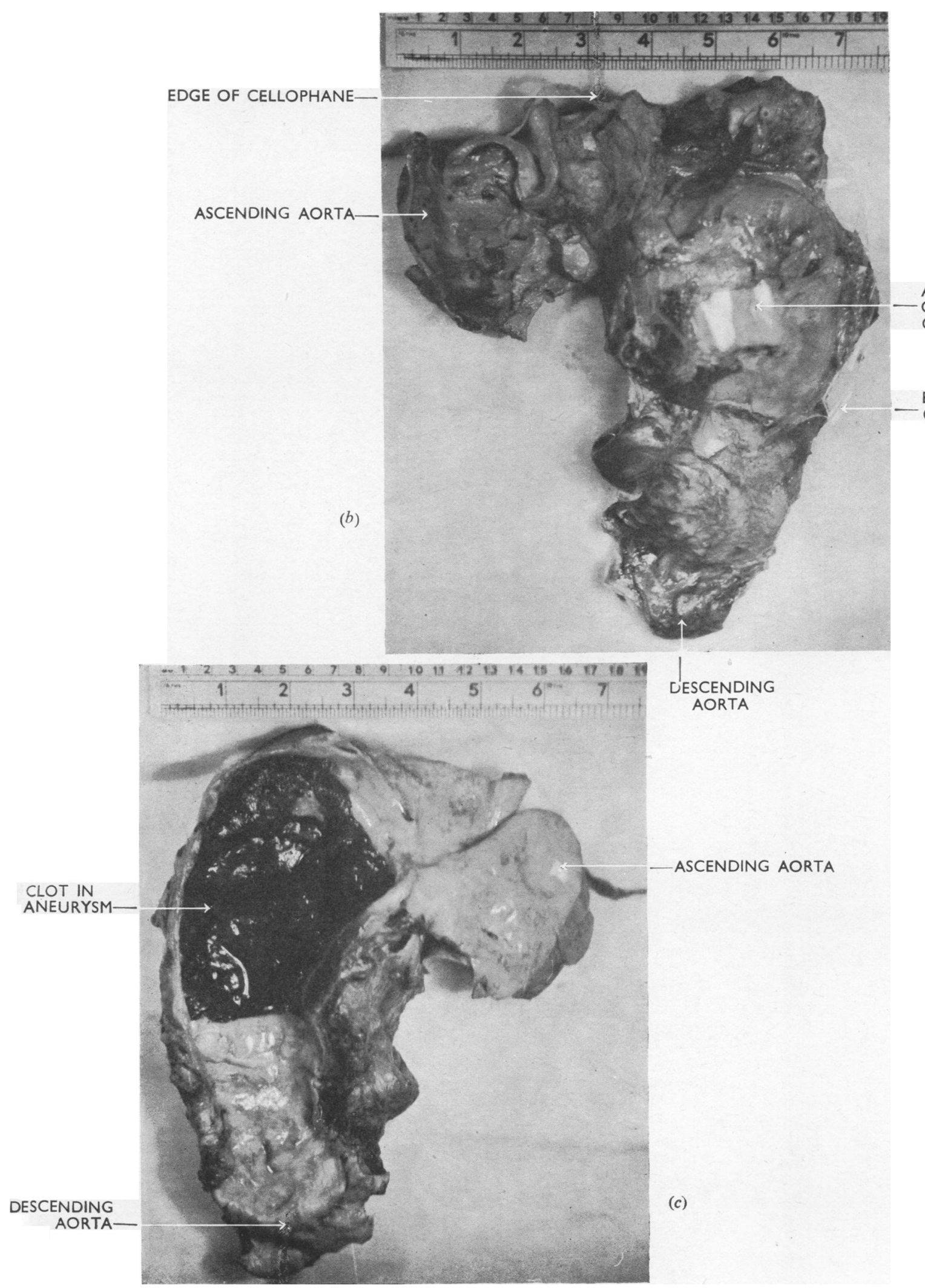

. 
The eleventh (No. 1175), C. D., aged 47, was explored on September 7, 1943, through a left thoracotomy, when a fusiform aneurysm, $3 \frac{1}{2}$ in. in length, was found at the junction of the arch and descending aorta. A further and smaller aneurysm was also found in the descending aorta just above the diaphragm. The patient lived three more years, finally dying from rupture of the aneurysm in 1946.

TABLE II

UNTREATED ANEURYSMS

\begin{tabular}{|c|c|c|c|c|c|}
\hline $\begin{array}{l}\text { Serial } \\
\text { No. }\end{array}$ & $\begin{array}{l}\text { Case } \\
\text { No. }\end{array}$ & $\begin{array}{l}\text { Present } \\
\text { State }\end{array}$ & Cause of Death & $\begin{array}{l}\text { Duration of } \\
\text { Life from Time } \\
\text { of Reporting }\end{array}$ & $\begin{array}{l}\text { Duration of Life } \\
\text { from Time of } \\
\text { First Symptoms }\end{array}$ \\
\hline 1 & 568 & Dead & Heart failure & $\begin{array}{l}6 \text { years } \\
\text { (See note) }\end{array}$ & $6 \frac{1}{4}$ years \\
\hline 2 & 819 & Dead & $\begin{array}{l}\text { Sudden death (rupture pre- } \\
\text { sumed) }\end{array}$ & 10 months & $2 \frac{110}{2}$ years \\
\hline $\begin{array}{l}3 \\
4\end{array}$ & $\begin{array}{l}1175 \\
2012\end{array}$ & $\begin{array}{l}\text { Dead } \\
\text { Dead }\end{array}$ & $\begin{array}{l}\text { Rupture aortic aneurysm } \\
\text { Exbaustion following oeso- } \\
\text { phageal obstruction from } \\
\text { aneurysm }\end{array}$ & $\begin{array}{l}3 \text { years } \\
1 \text { month }\end{array}$ & $\begin{array}{l}3 \frac{1}{6} \text { years } \\
1 \text { year }\end{array}$ \\
\hline $\begin{array}{l}5 \\
6\end{array}$ & $\begin{array}{l}2289 \\
2851\end{array}$ & $\begin{array}{l}\text { Dead } \\
\text { Dead }\end{array}$ & $\begin{array}{l}\text { Pneumonia } \\
\text { Rupture of aneurysm during } \\
\text { bronchoscopy }\end{array}$ & $\begin{array}{l}6 \text { days } \\
1 \text { day }\end{array}$ & $3 \frac{1}{2}$ years \\
\hline $\begin{array}{l}7 \\
8 \\
9\end{array}$ & $\begin{array}{l}2944 \\
3331 \\
3319\end{array}$ & $\begin{array}{l}\text { Dead } \\
\text { Not traced } \\
\text { Not traced }\end{array}$ & Rupture into trachea & 13 months & $\begin{array}{l}3 \text { years } \\
\frac{2}{12}+ \\
\frac{6}{12}+\end{array}$ \\
\hline 10 & 3433 & & $\begin{array}{l}\text { Rupture into bronchus while } \\
\text { straining at stool }\end{array}$ & 2 days & $1 \frac{1}{2}$ years \\
\hline $\begin{array}{l}11 \\
12\end{array}$ & $\begin{array}{l}4293 \\
5705\end{array}$ & $\begin{array}{l}\text { Dead } \\
\text { Alive }\end{array}$ & Heart failure with congestion & \multirow{2}{*}{\multicolumn{2}{|c|}{$\begin{array}{l}13 \text { months } \\
13 \text { months after onset of symptoms } \\
\text { and } 1 \text { year after diagnosis } \\
14 \text { months after onset of symptoms } \\
\text { and } 9 \text { months after diagnosis }\end{array}$}} \\
\hline 13 & 6135 & Alive & & & \\
\hline
\end{tabular}

\section{DEEP $X$-RAY THERAPY}

One patient received deep $x$-ray therapy because a wrong diagnosis of bronchogenic carcinoma had been made. This caused shrinking of the aneurysm and such lessening of tracheal obstruction that he was able to return to steady work as a blacksmith. Fourteen months later, at 2 a.m., he was awakened by a sudden spasm of coughing, had a profuse haemoptysis, and died.

\section{Cellophane Wrapping}

First described by Harrison and Chandy in 1943, this method has been claimed to produce fibrosis around the aneurysm on account of its irritant nature. Two fusiform aneurysms involving the descending aorta have been treated in this way.

Case Report.-(No. 3363) A woman, aged 50, was admitted on June 29, 1946, with a six-month history of difficulty in climbing stairs because of a feeling of tightness in the left chest localized to the third and fourth costal cartilages. She developed a hard cough, with frothy sputum. Occasionally she had difficulty in swallowing. On admission she was seen to be pale and ill, with signs of recent weight loss. The trachea, which was displaced to the left, had a marked systolic tug. There was precordial pulsation 

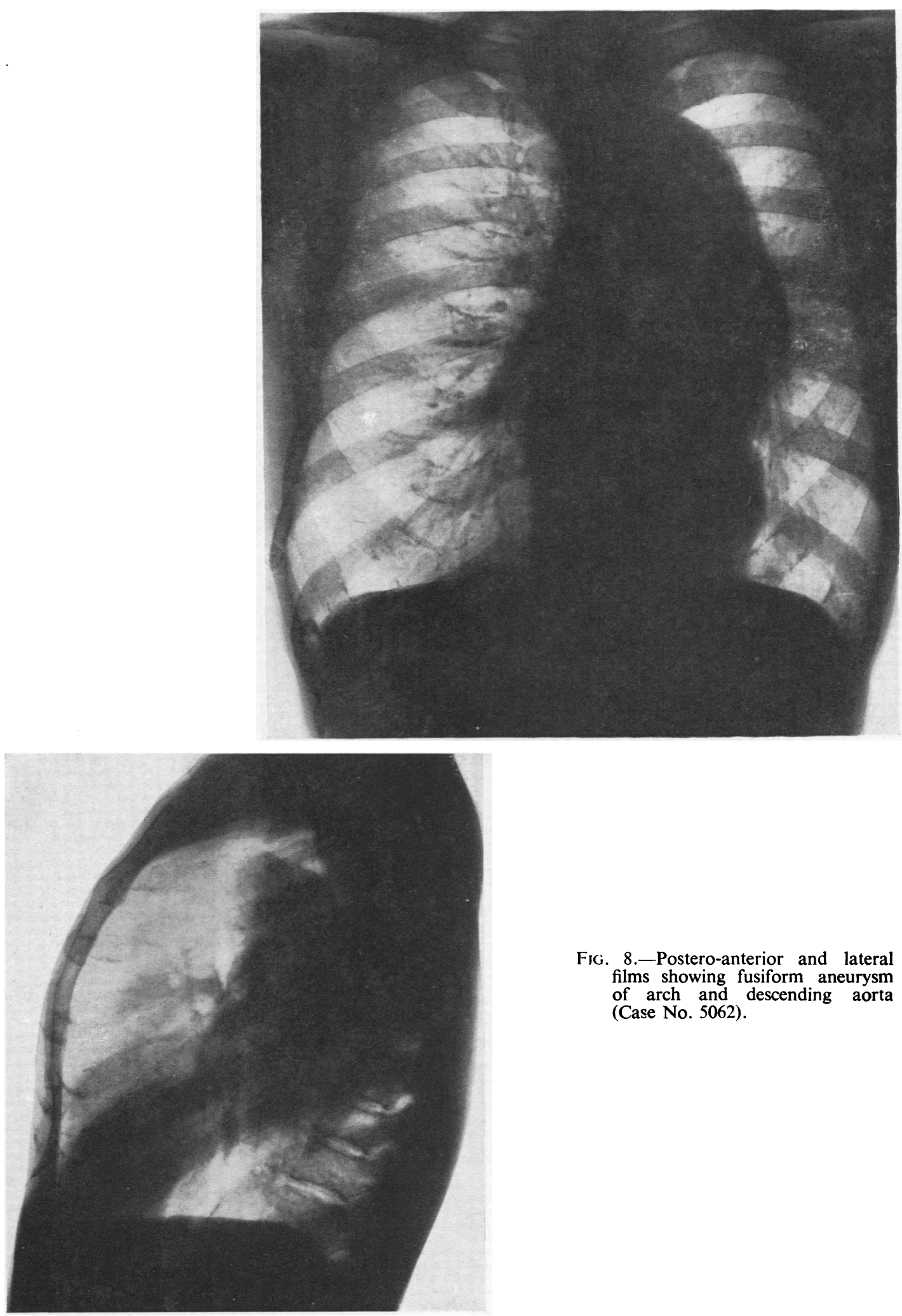

FIG. 8.-Postero-anterior and lateral films showing fusiform aneurysm of arch and descending aorta 
and an aortic systolic murmur with an accentuated second sound. Radial pulses were equal and the arm blood pressure was $200 / 90 \mathrm{~mm}$. Hg. She had clinical signs of tabes dorsalis. Bronchoscopy was performed and the result has been reported in Table I. Radiographs proved the presence of aneurysm. Because of its type and position, wiring was not possible and cellophane wrapping was advised (Fig. 7a).

Operation was performed on November 19, 1946, and the aneurysm was exposed through a postero-lateral thoracotomy. It was found to be smooth, pulsating, fusiform, and involving the descending aorta. The left lung, which lay over it and was adherent to its antero-lateral aspect, was easily separated by blunt dissection. A sheet of cellophane, cut to the required size, was placed over the aneurysm, completely covering its exposed surface, and was anchored in position by interrupted silk sutures. Convalescence was uneventful, and on January 5, 1947, the patient was discharged.

From May 1, 1947, until July 4, 1947, she was treated for heart failure with congestion. On January 18, 1950, she was readmitted in advanced general paralysis of the insane and died 10 days later.

A necropsy was performed. Immediately above the semilunar valve the aorta showed well-marked syphilitic aortitis. In the descending aorta there was a large aneurysmal sac with thick walls lined by a layer of blood clot. This spread completely around the aneurysmal wall. There was no thin portion of the wall which could have easily ruptured. The aortic lumen was patent. The aneurysm was enclosed in a cellophane covering which was fairly well attached to the external surface of the wall. It was not present in the area adherent to lung tissue (Figs. $7 b$ and $c$ ).

Case Report.-(No. 5062) A man, aged 47, was admitted on October 27, 1948, complaining of cough, blood-stained sputum for six months, shortness of breath, and stridor. There were no gross physical signs, but screening and radiological examination of the chest showed a fusiform aneurysm of the descending aorta (Fig. 8). The bronchoscopic findings have been reported in Table $I$.

Because of the depth of the aneurysm within the chest, its fusiform shape, and because of the recurring haemoptyses, cellophane wrapping was advised in an attempt to cause peri-aneurysmal fibrosis and intra-aneurysmal clotting.

The operation was performed on November 17, 1948, and through a left thoracotomy the aorta was exposed. Both the transverse arch and descending aorta were dilated. On the descending aorta there was an aneurysm the size of a fist, to which the apical segment of the lower lobe was adherent. Attempted separation of lung from the aneurysm resulted in a tear of the thin aneurysmal wall and haemorrhage, which was controlled by suturing lung once more to the surface of the aneurysm. A sheet of cellophane, cut to the required size, was sutured with interrupted sutures along the lateral side of the arch and descending aorta. Twenty-four hours after operation the patient suddenly died. At necropsy the aorta showed syphilitic aortitis, general dilatation, and a fusiform aneurysm of the descending part, as already described. This was filled with fresh, red blood clot. From this aneurysm a small opening led into the left lung. The left lung was completely collapsed; the bronchi contained blood-stained sticky mucus.

The cause of death was post-operative collapse of the left lung.

There is no doubt that in the first case the aneurysmal wall was reinforced with firm clot at the time of death, three years after operation. Nevertheless, it is impossible to be certain whether the clotting was spontaneous or the result of the peri-aneurysmal fibrosis that cellophane is said to produce. With such small experience of this treatment further comment is not possible. 
FIG. 9.-(a) Postero-anterior film showing aneurysm of ascending aorta before wiring (Case No 4817). (b) Lateral film of same patient after wiring. Note wire wisp in aneurysm.

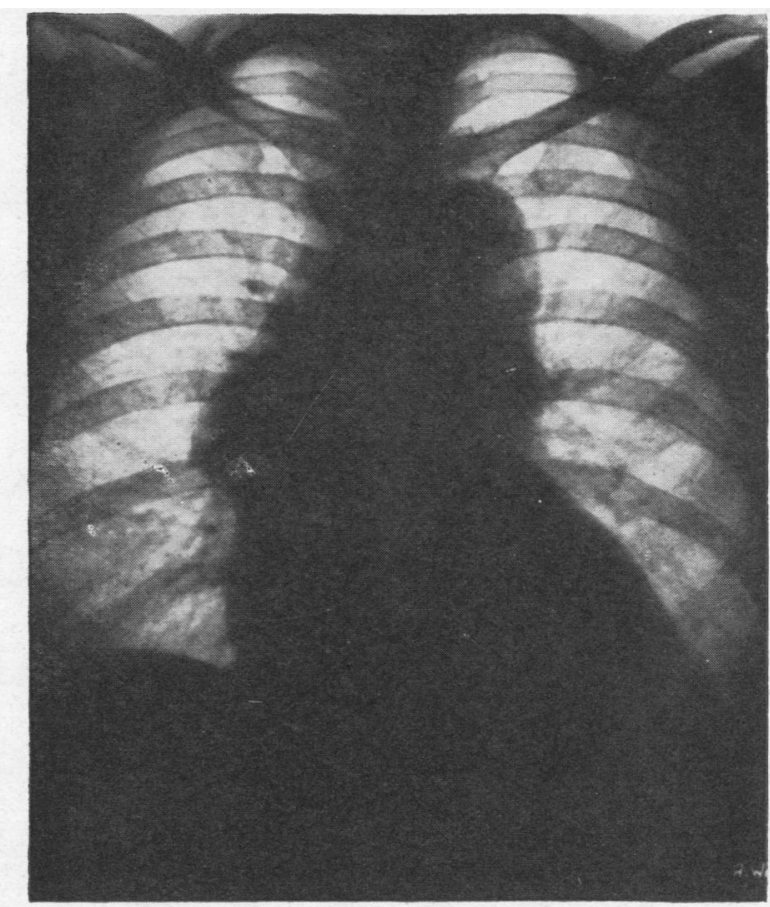




\section{Treatment by Colt's Wire WisP}

The aim is to cause clotting of blood within the aneurysm (Fig. 9). The resulting clot stops further growth of the aneurysm; it may cause shrinkage and thus relieve pressure symptoms. It also averts the danger of erosion and rupture into other thoracic viscera, e.g., trachea or oesophagus, or through bony chest wall and skin. Saccular aneurysms adherent to the bony chest wall are the most suitable for wiring by Colt's method.

Operative Technique.-The following operation note (November 17, 1936) illustrates the technique (Fig. 10) used.

Following careful localization of the aneurysm by radiography and clinical methods, novocain, $1 \%$, was introduced into the skin over the aneurysmal dilatation of aorta. The skin was pierced by a tenotome and the trocar and cannula inserted. The trocar was withdrawn. Blood spurted from the cannula. The cartridge containing the Colt's wire wisp was immediately inserted on to the end of the cannula. The wire wisp was then pushed into the aneurysm by the piston, the cannula withdrawn, and the puncture sealed with collodion.

More recently, blood has been aspirated from the aneurysm with a fine needle before inserting the trocar and cannula. This not only indicates the direction to be used with the trocar and cannula, but also shows the presence of an already existing intra-aneurysmal clot, if no blood can be aspirated.

We have had no experience of introducing the wire by open thoracotomy.

\section{THE RESULTS}

Nine aneurysms were wired with Colt's wire wisp. One patient, No. 5486, died as a direct result of wiring the aneurysm which, pre-operatively was suspected, and at necropsy proved, to be fusiform in shape. Clot caught in the meshes of the wire umbrella completely obstructed the aorta, with sudden death nine hours after operation. Two other patients (Cases 2 and 9) died as the result of tracheal compression for which the operation was performed. The former had pre-operative evidence of superior vena caval compression, later developing a recurring and severe stridor from which she died three months after operation. Bronchoscopy had shown the

TABLE III

Saccular Aneurysm Treated by Colt's Wire Umbrella

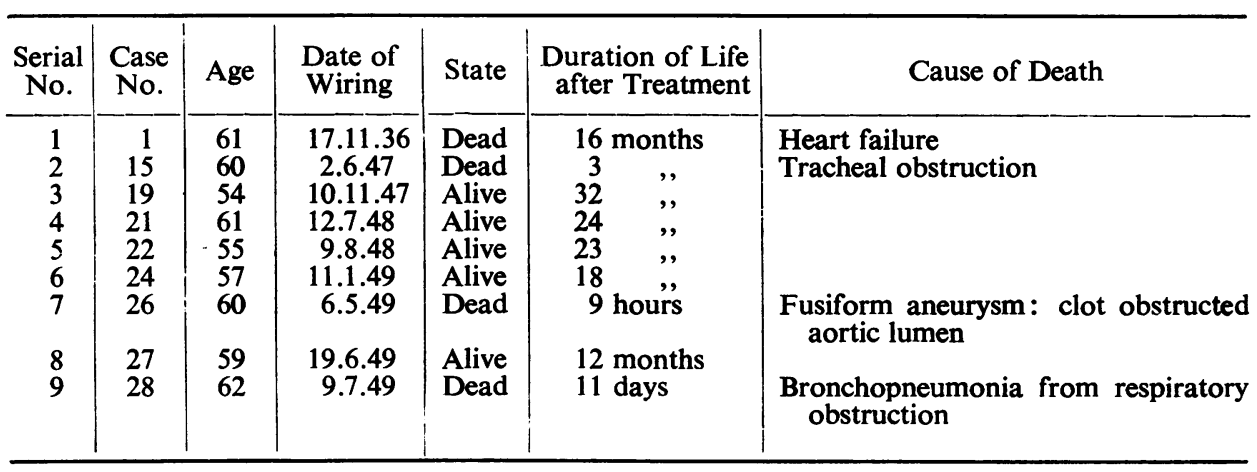




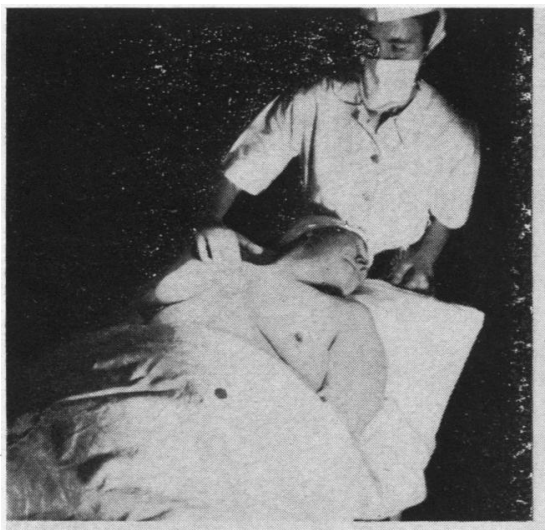

(a.) Pulsatile lump

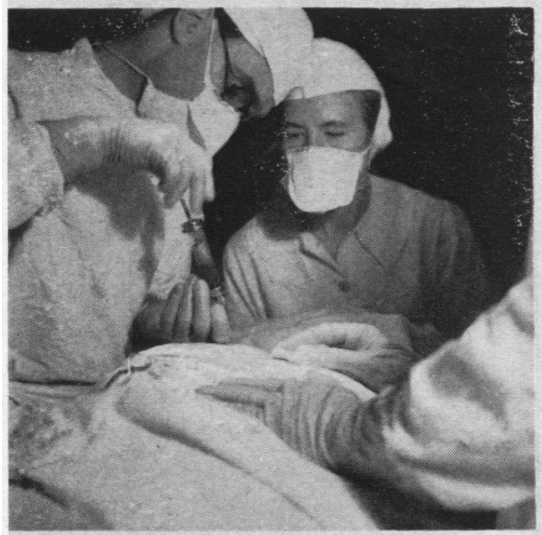

(c) Blood aspirated

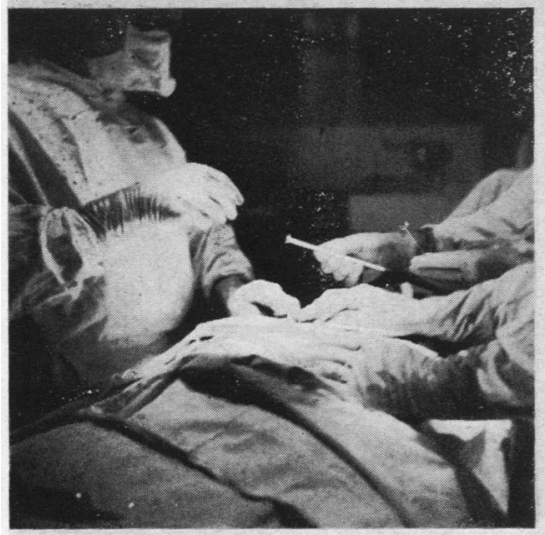

(e.) Cannula in aneurysm (trocar removed)

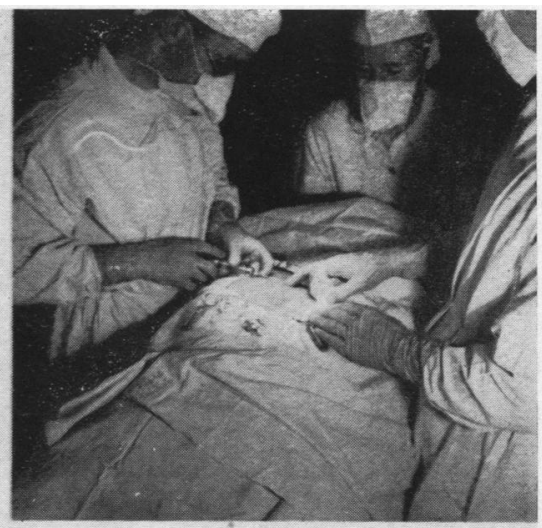

(b.) Local ancesthesia

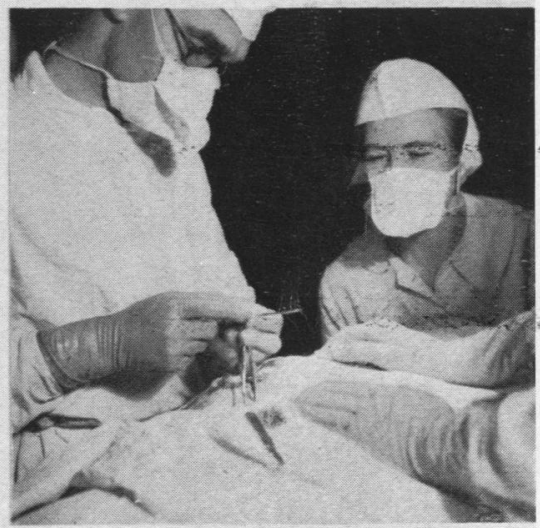

(d.) Trocar prepared

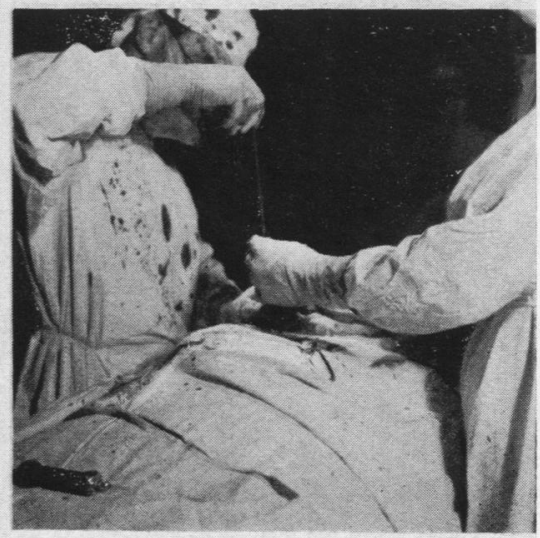

(f.)

Wire inserted

Fig. 10.-Technique of wiring an aneurysm. 

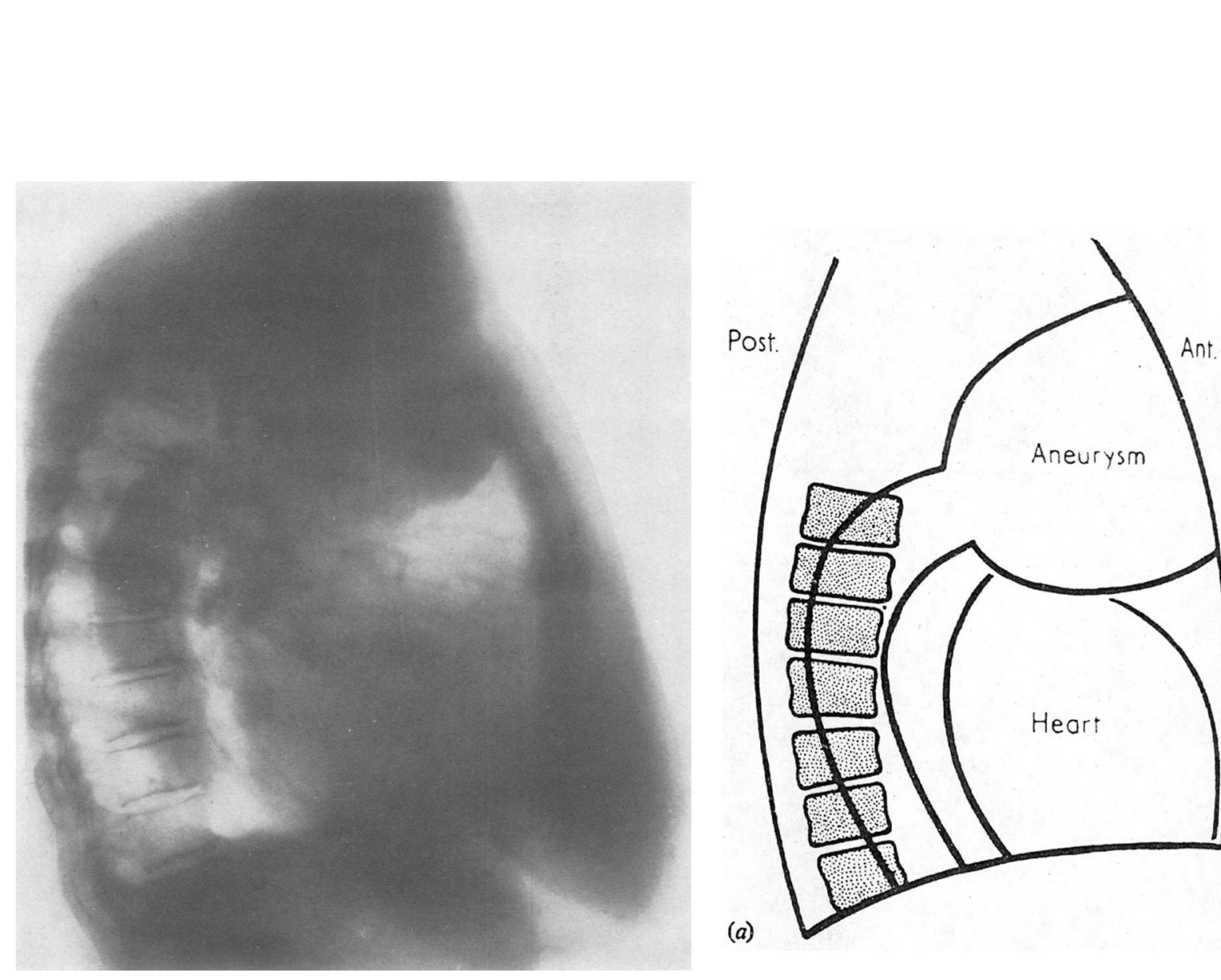

(a) 


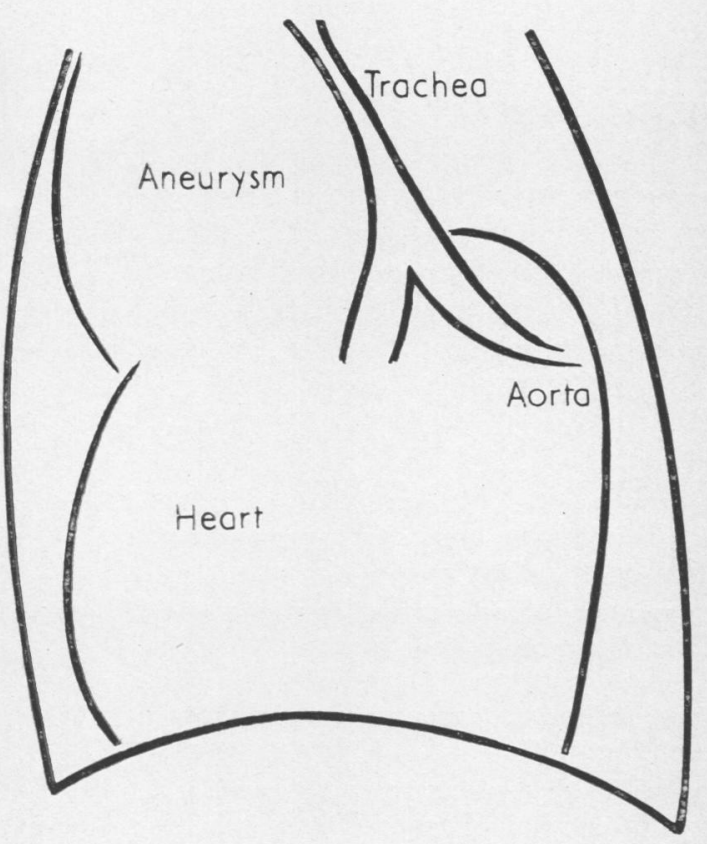

(b)
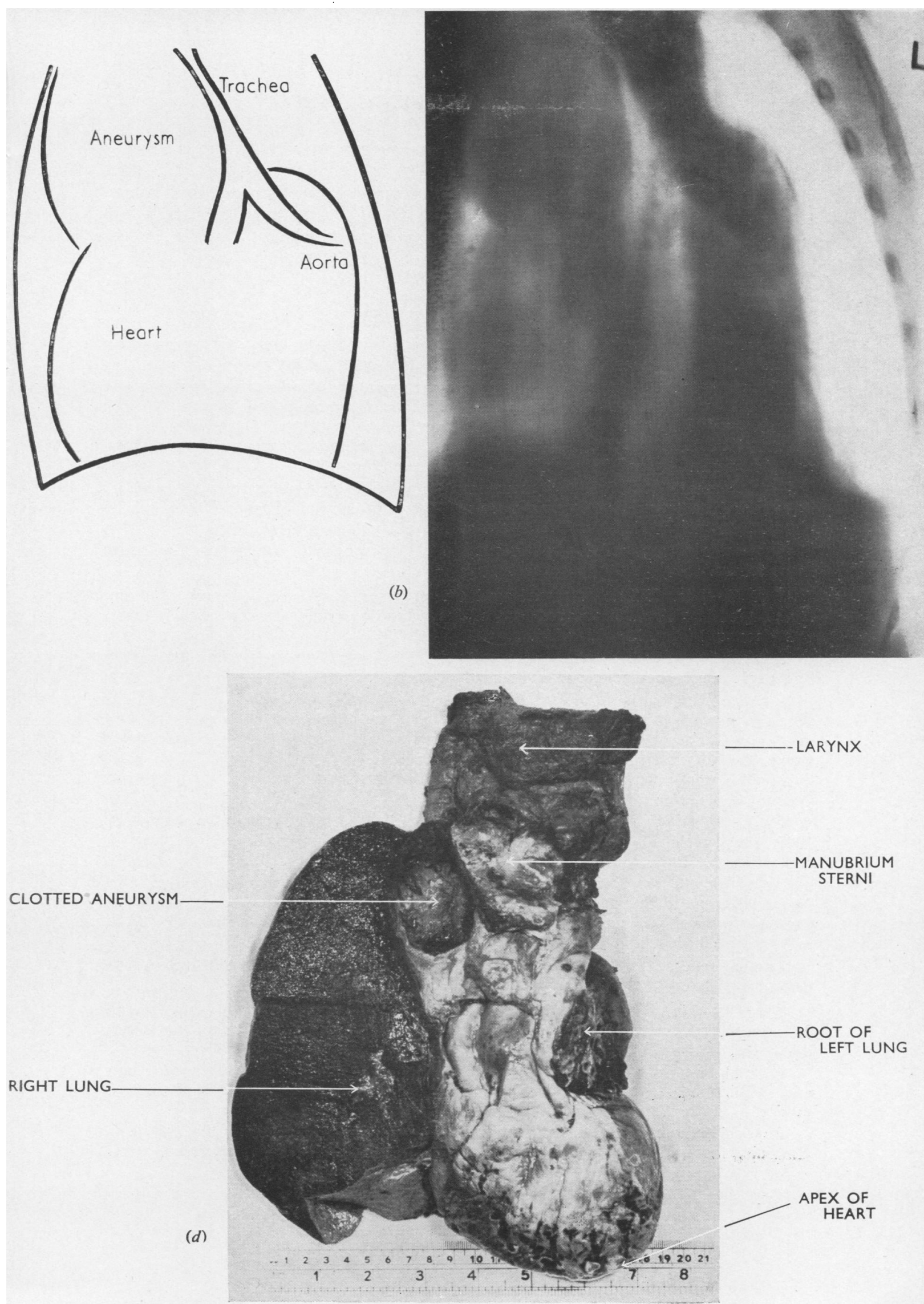
cords to be normal. The other patient, whose aneurysm was wired as an emergency because of respiratory obstruction, succumbed to bronchopneumonia 11 days after operation. The fourth death of the series occurred in 1938 from heart failure, 16 months after successful wiring of the aneurysm. The remaining five patients are alive and well and relieved not only of their symptoms but also of the acute danger of rupture of the aneurysm.

\section{CASE RePorts}

Case 1.-A man, aged 61, a labourer, had had symptoms for 12 months. A saccular aneurysm of the ascending aorta was diagnosed. Clinical features were progressive dyspnoea on exertion, with a painful, pulsatile lump on the right side of the chest.

There was a pulsating tumour in the second right intercostal space pushing the second rib forwards, a tracheal tug, and a diastolic murmur in the third and fourth right intercostal spaces. He had signs of heart failure with congestion, with a right pleural effusion and liver enlarged to the umbilicus. Blood pressure in the right arm was $126 / 64 \mathrm{~mm} . \mathrm{Hg}$ and in the left arm $136 / 68 \mathrm{~mm}$. $\mathrm{Hg}$.

On November 17, 1936, the aneurysm was wired with Colt's apparatus, and on December 11 a trocar and cannula were reinserted into the aneurysm. There was no bleeding on withdrawing the trocar; the aneurysm was thrombosed.

There was prompt relief of symptoms, but 16 months later the patient died from heart failure.

Case 2.-(No. 3942) A woman, aged 60, a domestic servant, had had symptoms for 12 months. A saccular aneurysm of the ascending and transverse arch of aorta was diagnosed (Figs. 11a, $b$, and $c$ ).

Clinical features were dilated neck veins for 12 months. Later, swelling of eyelids, lips, neck, chest, shoulders, and right hand occurred.

Physical examination showed distended cervical and chest veins consistent with superior vena caval compression. She had a "brassy," unproductive cough. The apex beat was in the left anterior axillary line, a mitral systolic murmur was heard along the left sternal border, and there was retrosternal dullness. The right wrist pulse was much stronger than the left wrist pulse. Blood pressure in the right arm was $260 / 130 \mathrm{~mm}$. $\mathrm{Hg}$ and in the left arm 130/?.

On June 2,1947, the aneurysm was wired with Colt's “wire wisp." On August 28, 1947, she developed laryngeal stridor, which increased in severity. She died on September 14, 1947.

At necropsy a saccular aneurysm of the aortic arch, "the size of an orange," was found adherent to the sternum and mediastinal surfaces of both lungs. It was firmly clotted. In the thoracic aorta there was another aneurysm, fusiform in shape and $1 \frac{1}{2}$ in. in diameter (Fig. 11d).

Though relieved for three months, the wiring was of temporary benefit only, as the patient died from tracheal compression.

Case 3.-(No. 4300) A woman, aged 54, a housewife, had had symptoms for 24 months. A saccular aneurysm of ascending and transverse arch of aorta was diagnosed.

Clinical features were a gradual onset of cough and hoarse voice over two years, and swelling below the left clavicle for nine months, with recent and rapid increase in size.

Physical examination showed swelling with expansile pulsation in the left infraclavicular fossa, a tracheal tug, apex beat $4 \frac{1}{2}$ in. to the left of the midsternum, a loud 
systolic murmur over the praecordium, and a diastolic murmur at the aortic area and over the swelling. Blood pressure was $130 / 60 \mathrm{~mm} . \mathrm{Hg}$ in the right arm and 120/? in the left arm.

On November 10, 1947, the aneurysm was wired with Colt's wisp, and on December 15, 1947 , in view of continued infra-clavicular pulsation, the aneurysm was needled in four places before re-wiring. It was filled with firm clot 2 in. in depth.

The aneurysm has remained stationary since operation. The patient was ambulant and well on June 20, 1950.

Case 4.-(No. 4719) A woman, aged 61, a housewife, had had symptoms for 18 months. A saccular aneurysm of the ascending arch of the aorta was diagnosed.

Clinical features were increasing dyspnoea for 18 months, cough, and a slowly growing lump to the right of the sternum.

Physical examination showed that over the lump, which showed expansile pulsation, a systolic murmur was audible. The trachea was displaced to the left. Blood pressure in the right arm was $190 / 110 \mathrm{~mm}$. $\mathrm{Hg}$.

On July 12, 1948, the aneurysm was wired with Colt's apparatus.

On June 20, 1950, the patient was symptomless and doing both housework and shopping. Blood pressure in each arm was $200 / 110 \mathrm{~mm}$. Hg. A systolic murmur was still audible over the aneurysm. Radiography showed the wire to be still in position. There was no increase in the size of the aneurysm.

Case 5.-(No. 4817) A woman, aged 55, housewife, had had symptoms for 12 months. A saccular aneurysm of the ascending aorta was diagnosed.

In July, 1947, she had experienced sudden severe pain in the right infra-clavicular fossa with radiation down the inner side of the right arm. She had been bedfast for the past two months.

Physical examination showed a pulsating swelling, most prominent in the second right intercostal space, anteriorly, but also extending into the neck. Blood pressure was $250 / 100 \mathrm{~mm}$. $\mathrm{Hg}$ in each arm.

On August 9, 1948, Colt's wire wisp was inserted.

The patient was well on June 12, 1950, and doing her own housework. There is still a small pulsation in the second right intercostal space, 2 in. from the mid-sternal line.

Radiography showed the wire still in position and no increase in size of the original aneurysm.

Case 6.-(No. 5209) A man, aged 57, a van driver, had had symptoms for four months. A saccular aneurysm of the ascending aorta was diagnosed (Fig. 12).

Clinical features were a "brassy" cough, and increasing dyspnoea with $9 \mathrm{oz}$. of thick, yellow sputum-at times blood-stained. The patient was bed-ridden, breathless at rest, with bilateral bronchopneumonia and areas of collapse in the middle and lower lobes of the right lung. The temperature was $100^{\circ} \mathrm{F}$. ; pulse, 120 ; respiration, 36 ; blood pressure, $160 / 100 \mathrm{~mm}$. Hg.

There was a pulsating mass in the superior mediastinum causing superior vena caval obstruction and gross narrowing of the trachea. The oesophagus was displaced to the left, and the mass extended forwards to contact the upper anterior chest wall at the level of the manubrium sterni. Bronchoscopy, of necessity performed in a sitting position, showed that the trachea was compressed to a mere transverse slit.

Following further deterioration despite penicillin and sulphamezathine, a Colt's wire wisp was inserted, hoping thereby to lessen the tracheal compression. Before the operation an endotracheal tube was inserted beyond the obstruction, under local anaesthesia. 


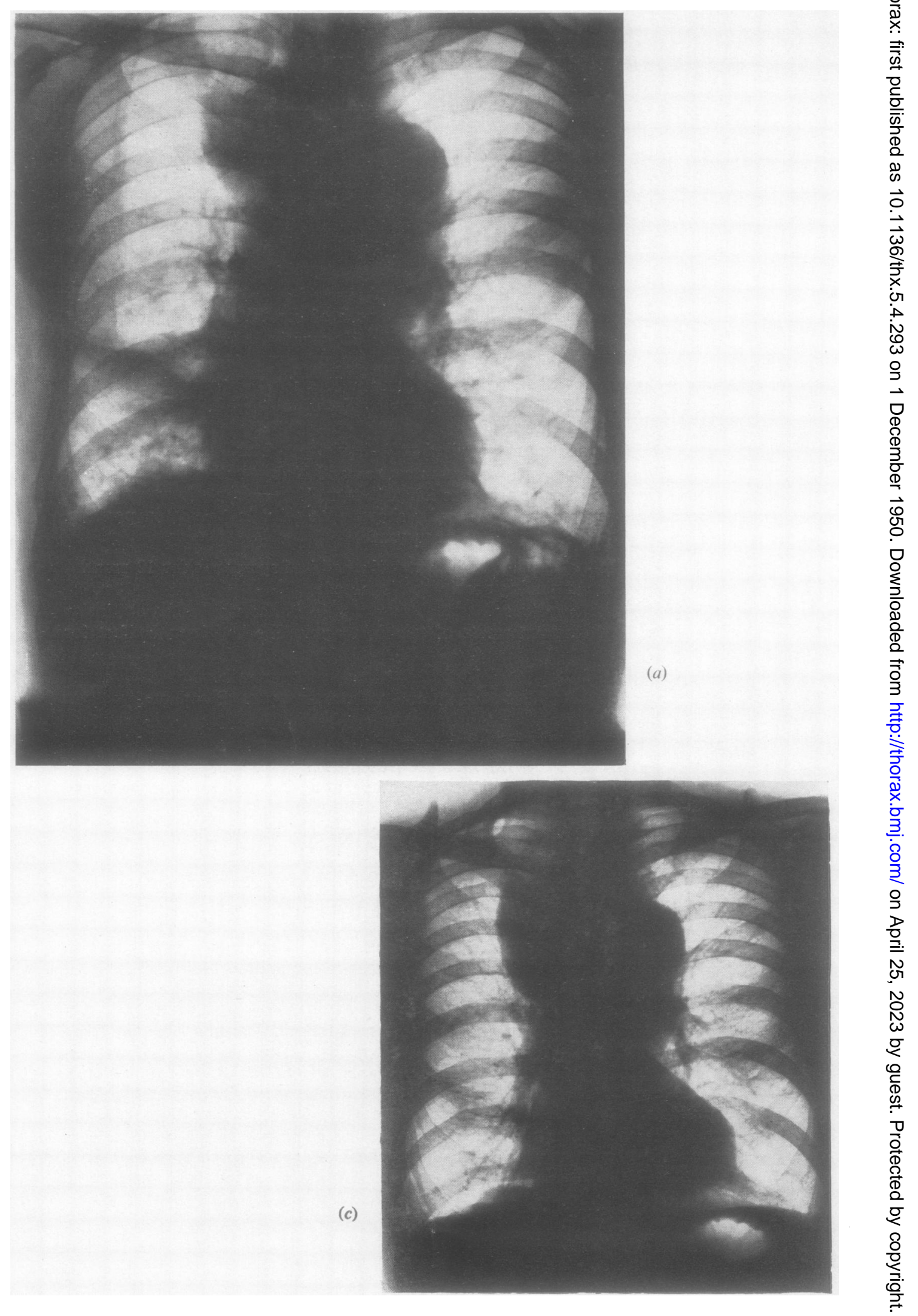




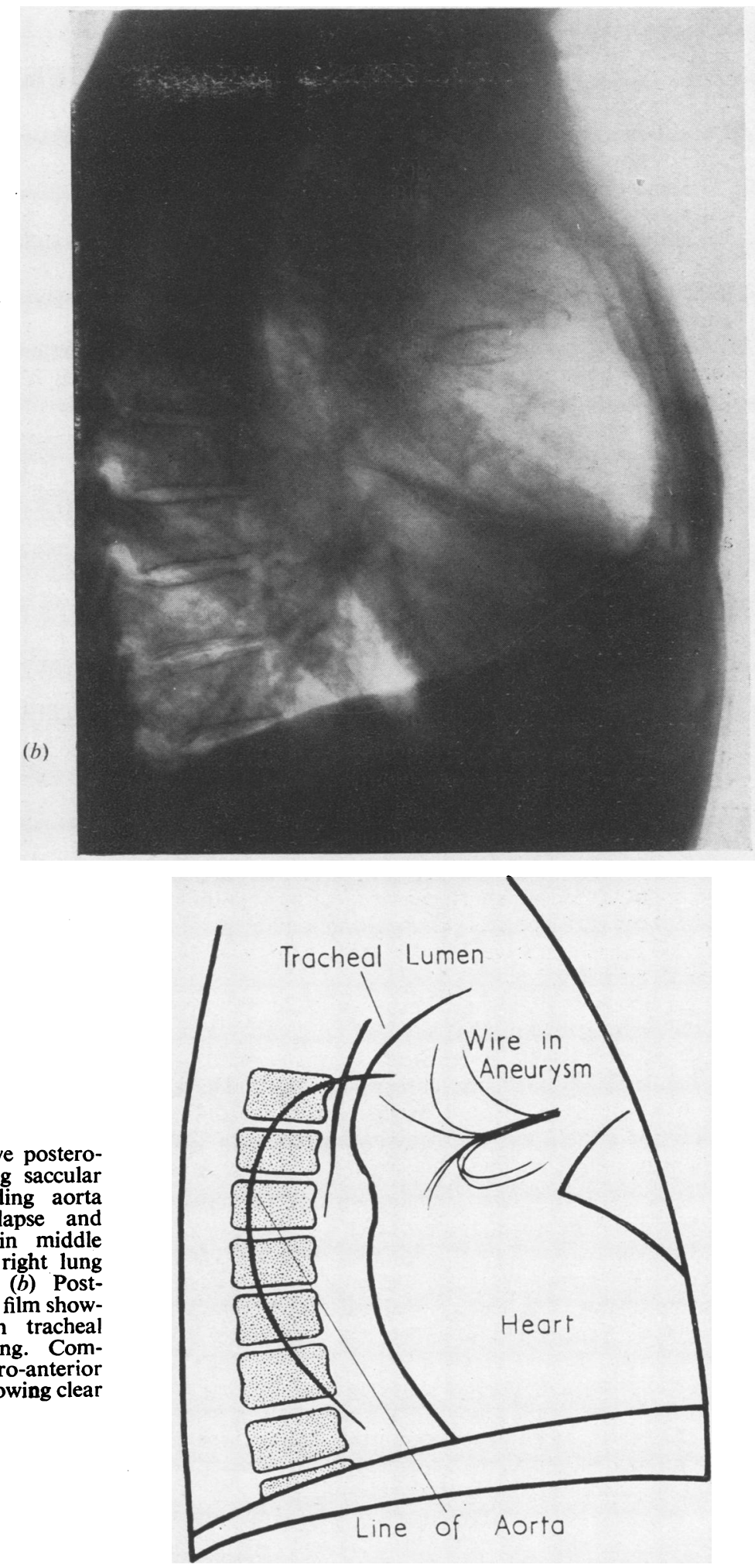

Fig. 12.-(a) Pre-operative posteroanterior film showing saccular aneurysm of ascending aorta with areas of collapse and bronchopneumonia in middle and lower lobes of right lung (Case No. 5209). (b) Postoperative right lateral film showing improvement in trachea lumen following wiring. Compare Fig. 4. (c) Postero-anterior film one year later showing clear lung fields. 
For the moment of wiring, owing to extreme distress, the patient was lightly anaesthetized with cyclopropane and oxygen.

The endotracheal tube was left in for 48 hours to allow a free airway and endobronchial suction.

His breathing improved and cough lessened. Radiography showed clearing of the lung fields, and bronchoscopy a marked improvement in tracheal lumen. Eighteen months later he had returned to work as a lorry driver. He still has occasional cough, sputum, and sometimes a mild stridor.

This case emphasizes an important principle, that no matter how severe the symptoms may be, an effort may be made to give the patient relief. With such aneurysms there is nothing to lose and everything to gain.

Case 7.-(No. 5486) A man, aged 60, a driller, had had symptoms for five months. A fusiform aneurysm of the ascending and transverse arches of aorta was diagnosed.

The patient had been bedfast, with general weakness, cough, and a sharp pain over the right scapula, for five months. Radiography showed aneurysmal dilatation of the ascending and transverse arch of aorta. He had gross neurosyphilis. Blood pressure in the right arm was $175 / 124 \mathrm{~mm}$. $\mathrm{Hg}$ and in the left arm $160 / 100 \mathrm{~mm}$. $\mathrm{Hg}$.

On May 6, 1949, the aneurysm was wired. Nine hours after operation the patient suddenly died.

At necropsy it was found that there was fusiform dilatation of the whole of the ascending aorta and about two-thirds of the transverse arch of the aorta. The entire circumference of the wall was involved. The dilatation stopped abruptly at the beginning of the descending aorta, which showed advanced syphilitic aortitis. The aneurysmal dilatation of the aorta was full of recent blood clot, which occluded the aortic lumen. In it was embedded the wire wisp.

Case 8.-(No. 5584) A man, aged 59, a handyman, had had symptoms for 12 months. A saccular aneurysm of the ascending aorta and transverse arch was diagnosed.

The patient had been bedfast with increasing cough for a year, loss of voice for two months, recent shortness of breath, and difficulty in swallowing even fluids. He had a "brassy" cough, a tracheal tug, an aortic "to and fro" murmur, and "Corrigan" pulse. Blood pressure in the right arm was $112 / 70 \mathrm{~mm} . \mathrm{Hg}$ and in the left arm 136/85 mm. Hg.

Bronchoscopy showed almost complete occlusion of the left bronchus and narrowing of the right bronchus (Table I).

On June 19, 1949, the aneurysm was wired.

On June 16, 1950, the patient was well. He was still hoarse, and, though swallowing had improved, he still experienced some difficulty. A barium swallow showed no oesophageal hold-up. Screening showed very little pulsation of the aneurysm. The collapsing pulse, tracheal tug, and cardiac murmurs were still detected.

Case 9.-(No. 5684) A man, aged 62, a miner, was diagnosed as having a saccular aneurysm of the ascending aorta.

Clinical features were increasing dyspnoea, cough, and hoarseness of voice for two years. His cough was now "brassy" and accompanied by half a cupful of greenish sputum a day. He had generalized moist sounds in both lungs. The trachea was displaced to the right and a tug was palpable. Blood pressure in the right arm was $120 / 95 \mathrm{~mm}$. $\mathrm{Hg}$ and in the left $110 / 90 \mathrm{~mm}$. $\mathrm{Hg}$.

Fluoroscopy showed an aneurysm of the ascending aorta, adherent to the chest wall anteriorly and displacing and compressing the trachea on its left lateral wall.

On July 9, 1949, as an emergency the aneurysm was wired.

On July 14, 1949, his “ bronchitis " progressed to bronchopneumonia, and on July 20, 1949 , he died. Necropsy was refused. 
Of three patients with innominate aneurysms one was relieved of symptoms for two years by decompression. The second died from endotracheal rupture two weeks after distal ligation. The third died from bronchopneumonia six days after admission and before active treatment could be performed.

There were 24 patients with aortic aneurysms. Of these 24,11 received no active treatment. Two others were explored. One died six years and the other three years after diagnosis. Two patients had not been traced. Of the remaining nine patients, seven were dead within fifteen months of diagnosis, and within three years of their first symptom. The final two, who are still alive, have been observed for nine months and five months respectively.

One patient, following a wrong diagnosis of bronchial carcinoma, received deep $x$-ray therapy. He died from rupture of the aneurysm 14 months later.

Two patients with fusiform aneurysms were treated by cellophane wrapping. One died 24 hours after operation from collapse of the left lung. The other died three years three months after operation from general paralysis of the insane. The aneurysmal wall was thickened and lined by a continuous layer of blood clot.

Nine patients were treated with Colt's wire. One, who had a fusiform aneurysm and thus was unsuitable for wiring by this method, died in nine hours from massive aortic clotting. Of two patients, both of whom had tracheal compression before operation, one died 11 days after emergency wiring from bronchopneumonia, and one in four months from recurrent tracheal obstruction. Five of the remaining six are alive and well between 12 and 32 months after operation. The sixth, wired in 1936, lived with relief of symptoms for 16 months.

\section{CONCLUSION}

We believe that accurate diagnosis of site and type of aneurysm, as well as determining its effect on the trachea and lungs, are essential in deciding correct treatment. Both wiring with a "wisp" to cause aneurysmal clotting, and wrapping with cellophane to cause both clotting and peri-aneurysmal fibrosis, thus limiting growth and preventing rupture, are important methods of relieving symptoms and prolonging life. Saccular aneurysms adherent to the chest wall are most suited to Colt's wiring technique. Although our experience is small, fusiform aneurysms seem most suited to cellophane wrapping.

\section{SUMMARY}

Twenty-four patients with aortic aneurysm and three with innominate aneurysm are reviewed.

Certain aspects of pathology, symptoms, signs, and methods of investigation are discussed.

Past methods of surgical treatment are surveyed and the principles underlying Colt's method of wiring re-stated.

Results of treatment in 14 patients are given.

Our thanks are due to Mr. George A. Mason, in whose clinic these cases were treated, for access to the relevant records, and to Dr. Whately Davidson for advice in connexion with radiographs. 


\section{REFERENCES}

Alexander, J., and Byron, F. (1944). J. Amer. med. Ass., 126, 1139.

Blakemore, A., and King, B. G. (1938). Ibid., 111, 1821.

(1945). Nelson New Loose-Leaf Surgery, vol. 1, chapter 12 B, p. 785. New York. (1947). Trans. Sth. Surg. Ass., 59, 27.

Blickman, J. R. (1949). Arch. Chir. neerl., 1, 50.

Colt, G. H. (1927). Quart. J. Med., 20, 331. (1948). 12 Congr. Soc. Int. Chir., p. 436.

Emmert, M. (1933). Neb. St. med. J., 18, 63.

Filippi, A. (1879). Sperimentale, 43, 445.

Harrison, P. W., and Chandy, J. (1943). Ann. Surg., 118, 478.

Monod, O., and Meyer, A. (1950). Circulation, 1, 220.

Moore, C. H., and Murchison, C. (1864). Med.-chir. Trans., 47, 129.

Page, I. H. (1939). J. Amer. med. Ass., 113, 2046.

Poppe, J. K. (1948). Amer. Heart J., 36, 252.

- and De Oliveira, H. R. (1946). J. thorac. Surg., 15, 186.

Power, D., and Colt, G. H. (1903). Med.-chir. Trans., 86, 363. (1903). Lancet, 2, 808.

\section{ADDENDUM}

Since submitting this paper for publication, two further syphilitic aneurysms of the innominate artery have been treated, both by Mr. Mason. The technique in each was the same.

So as to convert the lesion into a " saccular aneurysm of the aorta," the common carotid and right subclavian arteries were each ligated in continuity, distal to the aneurysms. Standard approaches to these arteries were used, and each was temporarily occluded with a Blalock clamp before tying the ligatures. Immediately after closure of the wound Colt's wire wisps were inserted into the aneurysms. Neither patient had any cerebral or brachial complication. The early post-operative results are satisfactory. 